\title{
Absence of the calcium-binding protein calretinin, not of calbindin D-28k, causes a permanent impairment of murine adult hippocampal neurogenesis
}

\author{
Kiran Todkar, Alessandra L. Scotti and Beat Schwaller*
}

Unit of Anatomy, Department of Medicine, University of Fribourg, Fribourg, Switzerland

Edited by:

Michael R. Kreutz, Leibniz-Institute

for Neurobiology, Germany

\section{Reviewed by:}

Miou Zhou, University of California

Los Angeles, CA, USA

Jose R. Naranjo, Centro Nacional de

Biotecnología, Spain

Cordula Nitsch, University of Basel,

Switzerland

\section{*Correspondence:}

Beat Schwaller, Unit of Anatomy, Department of Medicine, University of Fribourg, Route Albert-Gockel 1, $\mathrm{CH}-1700$ Fribourg, Switzerland. e-mail: beat.schwaller@unifr.ch
Calretinin (CR) and calbindin D-28k (CB) are cytosolic EF-hand $\mathrm{Ca}^{2+}$-binding proteins and function as $\mathrm{Ca}^{2+}$ buffers affecting the spatiotemporal aspects of $\mathrm{Ca}^{2+}$ transients and possibly also as $\mathrm{Ca}^{2+}$ sensors modulating signaling cascades. In the adult hippocampal circuitry, $\mathrm{CR}$ and $\mathrm{CB}$ are expressed in specific principal neurons and subsets of interneurons. In addition, $C R$ is transiently expressed within the neurogenic dentate gyrus (DG) niche. $\mathrm{CR}$ and $\mathrm{CB}$ expression during adult neurogenesis mark critical transition stages, onset of differentiation for $\mathrm{CR}$, and the switch to adult-like connectivity for $\mathrm{CB}$. Absence of either protein during these stages in null-mutant mice may have functional consequences and contribute to some aspects of the identified phenotypes. We report the impact of CR- and CB-deficiency on the proliferation and differentiation of progenitor cells within the subgranular zone (SGZ) neurogenic niche of the DG. Effects were evaluated (1) two and four weeks postnatally, during the transition period of the proliferative matrix to the adult state, and (2) in adult animals ( 3 months) to trace possible permanent changes in adult neurogenesis. The absence of CB from differentiated DG granule cells has no retrograde effect on the proliferative activity of progenitor cells, nor affects survival or migration/differentiation of newborn neurons in the adult DG including the SGZ. On the contrary, lack of $\mathrm{CR}$ from immature early postmitotic granule cells causes an early loss in proliferative capacity of the SGZ that is maintained into adult age, when it has a further impact on the migration/survival of newborn granule cells. The transient CR expression at the onset of adult neurogenesis differentiation may thus have two functions: (1) to serve as a self-maintenance signal for the pool of cells at the same stage of neurogenesis contributing to their survival/differentiation, and (2) it may contribute to retrograde signaling required for maintenance of the progenitor pool.

Keywords: calcium-binding, adult neurogenesis, dentate gyrus, calretinin, calbindin, calcium buffer, calcium sensor, subgranular zone

\section{INTRODUCTION}

Adult neurogenesis is the process of generating functional neurons from adult neuronal precursors. It requires the regulated, adaptive maintenance of a neurogenic proliferative matrix beyond prenatal and perinatal development into adult life (Altman and Bayer, 1990a). In the mammalian CNS this is accomplished in the subventricular zone and the subgranular zone (SGZ). The SGZ is located in the dentate gyrus (DG) of the hippocampus, along the lower border of the granule cell layer (GCL). Within the SGZ new excitatory granule neurons are born to migrate and synaptically integrate within the adjacent

\footnotetext{
Abbreviations: $\mathrm{BLBP}$, brain lipid-binding protein; BrdU, bromodeoxyuridine; $\mathrm{CB}$, calbindin D-28k; CR, calretinin; DAPI, 4',6'-diamidino-2-phenylindole; DCX, doublecortin; DG, dentate gyrus; GABA, gamma amino butyric acid; GCL, granule cell layer; GFAP, glial fibrillary acidic protein; IHC, immunohistochemistry; LTP, long-term potentiation; ML, molecular layer; PCNA, proliferating cell nuclear antigen; PSA-NCAM, polysialylated neural cell adhesion molecule; ROI, region of interest; SDS, sodium dodecyl sulfate; SGZ, subgranular zone; TCF-4, T-cell-specific transcription factor 4 ; WT, wild type.
}

principal neuron layer of the DG (Kempermann, 2011; Ming and Song, 2011). The pool of proliferating cells in the DG neurogenic niche is heterogeneous, consisting of few slowly dividing putative stem cells and numerous generations of progenitors with different and changing cell cycle rates, which eventually develop into postmitotic immature neurons. Putative stem cells characteristically express glial fibrillary acidic protein (GFAP), nestin, and brain lipid-binding protein (BLBP), while the progenitor pool can be distinguished by the expression of Tbr2, polysialylated neural cell adhesion molecule (PSA-NCAM) and doublecortin (DCX). Intermediate transitional stages are consistently present, characterized by proliferating cells typically expressing both nestin and DCX (Brown et al., 2003; Ming and Song, 2011; von Bohlen Und Halbach, 2011). Before cell cycle exit, progenitors realign their processes in a vertical direction and leave the SGZ to migrate a short distance into the lower granular layer at the border of the SGZ. The critical phase of cell cycle exit correlates with the onset of transient expression of the $\mathrm{Ca}^{2+}$-binding protein calretinin (CR) (Ming and Song, 2011; von Bohlen Und Halbach, 2011). 
Put on a timeline, most of the dividing progenitors labeled by a bromodeoxyuridine (BrdU) pulse will become CR-positive immature neurons within a week from BrdU injection. CR expression continues on average for an additional 2-3 weeks, but the percentage of BrdU and CR-positive cells then rapidly decreases (Brandt et al., 2003). Differentiating immature neurons are largely influenced by depolarizing gamma amino butyric acid (GABA) currents during the second week from birth (Ge et al., 2006): they rapidly grow axons toward the CA3 target region, ramify and grow dendrites toward the molecular layer (ML). By the end of the second week, immature granule cells receive synaptic glutamatergic input from perforant path terminals and release glutamate onto CA3 pyramidal cells (Faulkner et al., 2008; Ge et al., 2008). Synaptic targeting gradually continues and is refined over the next two weeks. The final step of synaptic integration consists in the targeting by basket and axo-axonic GABA-ergic synapses at about the end of the fourth week (Esposito et al., 2005). By this time most granule cells express the $\mathrm{Ca}^{2+}$-binding protein calbindin D-28k (CB) (Kempermann et al., 1997; Brandt et al., 2003), considered as a marker of their differentiated state (Ming and Song, 2011; von Bohlen Und Halbach, 2011). Both the proliferation and the differentiation stages are orchestrated by manifold interwoven signals aiming to maintain homeostasis and thus to preserve function of adult neurogenesis and related behavior (Kempermann, 2011; Ming and Song, 2011). It is interesting to note that the way immature neurons convey information from the entorhinal cortex to the CA3 region is qualitatively different from that of mature granule cells. Undifferentiated young neurons are more excitable and more prone to spread information to both the contralateral and distant ipsilateral DG, because they lack a strong inhibitory input and are densely connected to the hilar mossy cells commissural associational system (Henze and Buzsaki, 2007; Deng et al., 2009; Mongiat et al., 2009). In addition young granule cells are preferentially activated by specific stimuli and appear to strongly inhibit mature granule cells on their turn (Ge et al., 2008; Ming and Song, 2011; Toni and Sultan, 2011). Thus, mature and immature granule cells may represent two parallel information highways to the same target with different functions (Aimone et al., 2011; Ming and Song, 2011). There is accumulating evidence that, at a circuitry level, perforant path long-term potentiation (LTP) primarily relies on young adult born granule cells, suggesting that adult neurogenesis endows the DG with the potential for plasticity that this region requires to accomplish tasks like the continuous encoding of new memories and the discrimination between new and familiar information throughout life (Treves et al., 2008; Aimone et al., 2011; Ming and Song, 2011).

CR and $\mathrm{CB}$ belong to the large family of cytosolic EF-hand $\mathrm{Ca}^{2+}$-binding proteins, which bind $\mathrm{Ca}^{2+}$ ions with high affinity. They are well-known to function as $\mathrm{Ca}^{2+}$ buffers influencing the spatiotemporal aspects of $\mathrm{Ca}^{2+}$ transients within the cytosol (Schwaller, 2010). Recent evidence hints toward an additional/alternative role for $\mathrm{CB}$ and $\mathrm{CR}$ as $\mathrm{Ca}^{2+}$ sensors, capable of influencing signaling cascades in response to intracellular $\mathrm{Ca}^{2+}$ transients (Schwaller, 2009). Recent studies in mice lacking $\mathrm{CB}$ and $\mathrm{CR}$ by gene targeting confirm previous reports, indicating that both proteins are critical for many physiological properties (excitability, efficacy of synaptic release, resistance to hypoxia/ischemia) of the neuron expressing them and their absence may disrupt network function in some brain regions eventually affecting behavior (Schiffmann et al., 1999; Cheron et al., 2004; Schwaller et al., 2004; Farre-Castany et al., 2007; Stadler et al., 2010).

Evidence on the impact of $\mathrm{CB}$ or CR loss on hippocampal and, in particular, DG function is poor. In CB-deficient mice, hippocampal functional reserve appears curtailed: the normal asymptomatic age-dependent decline in DG metabolism, as estimated by rCBV, is significantly accelerated and is accompanied by a deficit in hippocampus-dependent learning in the active place avoidance task (Moreno et al., 2011). In addition, CB with its fast $\mathrm{Ca}^{2+}$-binding properties is pivotal for mature granule cell function within the hippocampal system as reported before (for details, see Schwaller, 2010). In CR-deficient mice, LTP is selectively impaired in the DG, but not the CA1 region. The disturbed DG synaptic plasticity is attributed to the absence of CR from the local hilar mossy cells resulting in changes in excitability of the DG network. Contrarily to what was reported for CBdeficient mice, the deficit at the circuitry level in $\mathrm{CR}^{-/-}$mice does not seem to affect hippocampal-dependent spatial learning in the Morris water maze (Schurmans et al., 1997; Gurden et al., 1998). CB and CR are normally expressed in many different neuronal types within the hippocampal circuitry including subsets of interneurons and the observed deficit at the phenotype level may therefore depend on which neurons are affected the most and how their "malfunction" may act additive or synergistic. CR and CB expression during the process of adult neurogenesis mark critical transition stages, i.e., onset of differentiation for CR and the shift to adult-like connectivity for $\mathrm{CB}$. The absence of the respective $\mathrm{Ca}^{2+}$ sensor/buffer at these stages may well have functional consequences and contribute to the reported phenotypes. In this study, we investigated whether the constitutive absence of either CR or $\mathrm{CB}$ would have any consequences on the balance between proliferation and differentiation within the SGZ neurogenic niche of the DG. We decided to examine the different genotypes (I) at young age (P14 and P28), during the important transition period of the proliferative matrix into the adult state, and (II) in adult animals (12-14 weeks of age) to trace probable permanent changes.

\section{MATERIALS AND METHODS ANIMALS}

Thirty CR-deficient $\left(\mathrm{CR}^{-/-}\right)$mice (Schurmans et al., 1997) and thirty $\mathrm{CB}$-deficient $\left(\mathrm{CB}^{-/-}\right)$mice (Airaksinen et al., 1997) backcrossed to $\mathrm{C} 57 \mathrm{BL} / 6 \mathrm{~J}$ for 10 generations and thus considered as congenic to $\mathrm{C} 57 \mathrm{BL} / 6 \mathrm{~J}$ were used for the experiments. C57BL/6J wild type (WT) animals $(n=30)$ were used as control. Animals were bred and housed in a SPF facility under adequate temperature $\left(23^{\circ} \mathrm{C}\right)$ and humidity $(60 \%)$ control with a $12 \mathrm{~h} / 12 \mathrm{~h}$ light/dark cycle (light onset at 7 a.m.) and provided with free access to water and food. Animals were sacrificed at 2, 4, and 14 weeks of age under deep anesthesia with $0.1 \%$ Eutha 77 in physiological saline (Essex Animal Health, Friesoythe, Germany). Cervical dislocation and fresh dissection of the brain was used for biochemistry experiments ( $n=8$ per genotype); transcardial perfusion fixation with buffered paraformaldehyde for morphology 
( $n=22$ per genotype). All experiments were performed with permission of the local animal care committee and according to the present Swiss law and the EU Directive (86/609/EEC) and Appendix A of the Council of Europe Convention ETS123, EU decree 2001-486 Decree 214/97.

\section{SUBSTANCE ADMINISTRATION}

The thymidine analogue BrdU was administered intraperitoneally to mice to label proliferating cells. BrdU is taken up by cells undergoing DNA synthesis and can be visualized post-hoc by immunohistochemistry (IHC) techniques. The BrdU solution for injection was prepared in sterile saline at $20 \mathrm{mg} / \mathrm{ml}$ and the dose injected was of $2 \mathrm{mg} / 10 \mathrm{~g}$ mouse for the proliferation assay and of $1 \mathrm{mg} / 10 \mathrm{~g}$ mouse for the differentiation assay, respectively.

Proliferation in the DG stem cell niche was estimated in 2 weeks old mice ( $n=6$ per genotype) by sacrificing animals $24 \mathrm{~h}$ after a single dose BrdU injection. Long-term survival and differentiation of dividing cells in the niche was estimated in adult 12 weeks old mice ( $n=5$ per genotype). These mice were injected once a day for three consecutive days and sacrificed for analysis 2 weeks after the last BrdU injection.

\section{BIOCHEMISTRY (WESTERN BLOT ANALYSIS)}

Five animals per group were used for the analysis at 2 weeks of age and three per group were sacrificed at 4 weeks of age. The whole hippocampus was dissected out of the fresh brain in ice-cold $0.9 \% \mathrm{NaCl}$ and stored at $-75^{\circ} \mathrm{C}$ to prevent protein degradation until further processing. Tissue samples were lysed with $250 \mu \mathrm{l}$ of RIPA buffer (Plumpe et al., 2006), homogenized and the protein concentration was measured with protein DC assay (Bio-Rad Laboratories, Inc., USA). The whole-cell extract was used for Western blotting. Samples were prepared by denaturing the protein lysates in Laemmli buffer and loaded on sodium dodecyl sulphate (SDS)-polyacrylamide gels (12\%) for separation. Proteins of interest had molecular weights in the range of $29 \mathrm{kDa}-40 \mathrm{kDa}$ (CR: $30 \mathrm{kDa}$; CB: $28 \mathrm{kDa}$; proliferating cell nuclear antigen (PCNA): $36 \mathrm{kDa}$; DCX: $40 \mathrm{kDa}$ ); 10-15 $\mu \mathrm{g}$ protein extracts were loaded on $1 \mathrm{~mm}$ thick gels. After transfer to a nitrocellulose membrane (Bio-Rad), a Ponceau Red staining was performed and documented (BIOCAPT software) to test for uniform loading and transfer of protein samples. After destaining, the membranes were incubated first in blocking buffer (Odissey, LI-COR GmbH, Germany) and then overnight with the primary antibody diluted 1:1000 in the same buffer. The following antibodies were used: mouse anti PCNA (Chemicon); goat anti DCX C-18 (Santa Cruz Biotechnology); rabbit anti CR 7696 and rabbit anti CB 38a (both Swant).

The appropriate secondary antibody was selected depending on the emission wavelength (IRDye 680, IRDye 800; Odissey) and the source of the primary antibody. Secondary antibodies were all diluted 1:5000. The Odyssey image analyzer was used to scan images at different intensities. Densitometric analysis was performed with the GeneTools software (Syngene, CA, UK). The intensity of a specific protein band was normalized to the intensity of the Ponceau Red staining of the same lane. The mean optical density ratio value for the WT samples was set as $100 \%$ and those of $\mathrm{CR}^{-/-}$and $\mathrm{CB}^{-/-}$mice were normalized to the WT values. All statistical analyzes were performed with student's $T$-test, two samples, using the Welch correction for unequal variances whenever necessary (Prism, Graphpad). The level of significance was assumed to be $p<0.05$.

\section{IMMUNOHISTOCHEMISTRY}

Animals perfused at 2 weeks of age were 10 per genotype; those perfused at 4 weeks of age were 4 per genotype and those sacrificed at 14 weeks of age were 8 per genotype (numbers include the mice used for BrdU injections). After transcardial perfusion fixation, the brains were dissected out of the skull and postfixed with gentle shaking in the same fixative solution $(4 \%$ paraformaldehyde in $0.1 \mathrm{M}$ phosphate buffer, $\mathrm{pH} 7.3$ ) for $24 \mathrm{~h}$ at $4^{\circ} \mathrm{C}$. They were then transferred to a $0.1 \mathrm{M}$ Tris-buffered saline solution containing $18 \%$ sucrose and $0.01 \% \mathrm{Na}$-azide for cryoprotection and were kept at $4^{\circ} \mathrm{C}$ until they sank to the bottom of the vial. Serial coronal sections, $40 \mu \mathrm{m}$ thick, were cut with a freezing microtome (Reichert-Jung, Nussloch, Germany) and collected in six wells plates at a $240 \mu \mathrm{m}$ interval (i.e., each section within a well is $240 \mu \mathrm{m}$ apart from the previous/next section). The primary antibodies used and their dilutions are as follows: mouse anti PCNA 1:500 (Chemicon); mouse anti BrdU 1:100 (Dakocytomation); mouse anti T-cell-specific transcription factor 4 (TCF-4) 1:50 (Abnova); goat anti DCX C-18 1:250 (Santa Cruz Biotechnology); rabbit anti CR 1:1000 and rabbit anti CB 1:2500 (both Swant). Pretreatments differed from antibody to antibody. In general, sections were permeabilized with Triton X$100(0.1-0.3 \%$ in phosphate buffered saline for $1-2 \mathrm{~h})$ to facilitate penetration of the reagents. PCNA and TCF- 4 immunolabelings required antigen retrieval pretreatment with $0.01 \mathrm{M}$ citric buffer. This treatment was performed at $120^{\circ} \mathrm{C}$ in a steamer for the PCNA labeling and at $80^{\circ} \mathrm{C}$ in a dry oven for the TCF- 4 labeling. The antigen retrieval step for the DCX labeling was carried out in $0.3 \%$ hydrogen peroxide in phosphate buffered saline for $30 \mathrm{~min}$ at room temperature. To improve the binding of the anti BrdU antibody a 30 min treatment with $2 \mathrm{M}$ $\mathrm{HCl}$, in a $37^{\circ} \mathrm{C}$ water bath, was performed in order to partially denaturate DNA (Brown et al., 2003). Antibodies were diluted either in $2 \%$ horse serum or $10 \%$ bovine serum and incubated overnight in the cold room $\left(4^{\circ} \mathrm{C}\right)$ with gentle shaking. For single labeling and visualization with the diaminobenzidine dye, we used biotinylated secondary antibodies and the avidinbiotin peroxidase technique (ABC kit, Rectolab SA). A subset of those sections labeled for nuclear antigens (BrdU and PCNA) were counterstained with the hematoxylin-eosin stain. Sections were dehydrated in increasing ethanol concentrations and xylene and then coverslipped with Entellan. For multiple labeling, fluorochrome conjugated secondary antibodies were used instead and the mounted sections were coverslipped in glycerol supplemented with an antifade reagent (Invitrogen cat. No. S2828). Note that for the multiple immunofluorescence labeling we avoided parallel incubation of the antibodies and preferred a serial labeling protocol to minimize cross-reaction risks. A subset of the doublelabeled sections was additionally counterstained with the nuclear stain 4',6-diamidino-2-phenylindole (DAPI) $(1 \mu \mathrm{g} / \mathrm{ml})$. Images were taken on an upright ZEISS light contrast microscope or 
on an inverse Leica SP5 confocal microscope equipped with the following laser excitation lines: $405 \mathrm{~nm}, 488 \mathrm{~nm}$ and $633 \mathrm{~nm}$.

To quantify the changes in signal intensity of DCX within the dendrites and the perikarya of newborn granule cells, we chose fluorochrome-labeled sections of 4 weeks old WT and $\mathrm{CR}^{-/-}$ mice ( $n=4$ per genotype). Measurements were performed on selected images with the same magnification using the software Image J (Tony Collins, 2009 release www.macbiophotonics.ca/ imagej/). Eight bit images $(1024 \times 1024$ pixels $)$ were viewed with the lookup table HiLo, which displays the zero values blue and the 255 white values red. A region of interest $(\mathrm{ROI})$ of $80 \times 80$ pixels was defined within the hilus of the DG and used for background subtraction from the ROI. DCX-labeled dendrites were outlined within the granular layer and the ML of the DG (10-30 profiles per image). DCX-labeled cell bodies were selected within the SGZ (6-15 profiles per image). Mean intensity, area in square pixels and the fraction of the area displaying intensity values above background were measured for each profile. A dendrite to soma intensity ratio per image was calculated using the corrected total mean density values per pixel of the dendritic and the somatic profiles. Statistics were performed as described above for Western blot analysis.

\section{MORPHOMETRIC ANALYSIS}

Nuclei immunolabeled for PCNA or TCF-4 in the GCL and the SGZ of the hippocampal DG were counted in 2 weeks and 4 weeks old animals, to quantify putatively dividing cells in the cells in the DG stem cell niche. The mean density of PCNA-positive nuclei was additionally determined in adult mice of 14 weeks of age. The analysis was restricted to the septal hippocampus and cells were counted in three coronal sections per animal (bregma levels $-1.46 ;-2.00 ;-2.30 \pm 0.05 \mathrm{~mm}$ ) for a total of six hippocampal regions per animal. The length of the SGZ was measured for each hippocampus and density values were expressed as the number of cells per mm length, pooled and averaged. This value was used then for group statistics. BrdU counts to estimate proliferative activity in the septal SGZ were only performed in 2 weeks old animals and analyzed as described for PCNA and TCF-4.

To study the survival/differentiation of the SGZ progeny in 14 weeks old animals sacrificed 2 weeks after the last BrdU injection, we determined the total number of BrdU-positive cells in the SGZ along its whole septotemporal extent. Cells were counted in eight serial coronal sections approx. two hundred and forty micrometer apart from each other (bregma level -1.22 to $-3.20 \pm 0.05 \mathrm{~mm}$ ) for a total of 16 hippocampal regions. The sum of these values was calculated and extrapolated to the total number of BrdU-labeled SGZ/DG cells per brain multiplying it by 6 (since only every sixth section had effectively been counted). Since however, cell location was not limited to the SGZ, but also included the DG, subset counts were performed in the following regions: (1) the SGZ, between the inner border of the GCL and the hilus; (2) GCL corresponding to the cell band and (3) GCL/ML corresponding to the outer border of the GCL (see Figure 6C). Statistical analysis was performed with the Prism software (Graph Pad, USA). Statistical comparisons between genotypes were performed with student's T-test, two samples, correcting for unequal variances whenever necessary (Welch correction).
Statistical comparisons within WT, or mutants at different time points were performed by one-way ANOVA using the Tukey test as a post-hoc test. The level of significance was assumed to be $p<0.05$.

\section{RESULTS \\ DENTATE GYRUS MORPHOGENESIS IS NORMAL IN THE ABSENCE OF CR AND CB}

The first observation in both null-mutant strains $\left(\mathrm{CR}^{-/-}\right.$and $\mathrm{CB}^{-/-}$) was that the general appearance of the DG is normal as shown in Figures 1, 3, 6 and 7. The thickness (height) of the GCL is normal, as well as the morphology of the mature granule cells (CB-ir in WT and $\mathrm{CR}^{-/-}$mice) and the not-yet fully differentiated ones bordering to the SGZ (CB-negative in WT and $\mathrm{CR}^{-/-}$ mice). The length and shape of the GCL/SGZ did not differ in mutant mice in comparison to WT animals, neither in young (2-4 weeks) animals nor in adults (12-14 weeks). Thus, both DG blades properly form during late embryonic and early postnatal development and the two proteins seem not to be involved in the control of this developmental process.

\section{LOW PROLIFERATIVE CAPACITY IN THE SGZ OF YOUNG (P14) CR $^{-/-}$MICE IS MAINTAINED INTO ADULT LIFE}

To screen for changes in the SGZ in $\mathrm{CR}^{-/-}$mice, we first examined the protein content, the signal intensity and distribution of DCX and CB in 2 and 4 weeks old animals. At 2 weeks of age, morphogenesis of the infrapyramidal blade of the DG is well completed, the proliferative matrix has rearranged along the SGZ and implementation of the inner third of the adult DG is ongoing, a gradual process that lasts till the end of the first postnatal month (Altman and Bayer, 1990a,b; Li and Pleasure, 2005). DCX expression within the DG SGZ is characteristic for proliferating progenitors and to a minor extent for early postmitotic neurons (Brown et al., 2003; Ming and Song, 2011; von Bohlen Und Halbach, 2011). On the other hand CB is a marker for mature granule cells (Baimbridge et al., 1992; von Bohlen Und Halbach, 2011). The large majority of newborn neurons express CB by the fourth week past their birth (Kempermann et al., 1997; Brandt et al., 2003). DCX and CB protein contents in whole hippocampal lysates were not different in $\mathrm{CR}^{-/-}$mice (Figures 1A,B). As expected for 2-4 weeks old animals, CB labeling did not encompass the whole width of the DG (Figure 1C). A clear gradient existed between the mature strong CB-ir GCL neurons and the young $\mathrm{CB}$-negative neurons located within the lower third of the GCL, at the border to the SGZ; this is best seen in the merged (DAPI/CB/DCX) image of Figure 1C. CB staining intensity was rather variable between sections from different mice. Changes in the labeling intensity with time or between genotypes were not consistent and probably reflect individual variability in $\mathrm{CB}$ expression during this phase of adjustment and definitive maturation of the DG (Altman and Bayer, 1990a,b; Li and Pleasure, 2005). The DCX staining intensity within the SGZ, GCL and ML was consistently decreased in 2 weeks and 4 weeks old $\mathrm{CR}^{-/-}$mutants as compared to WT. The signal appeared particularly low within the dendrites in the 4 weeks old $\mathrm{CR}^{-/-}$ group, as if DCX would preferentially label the cell bodies rather than the processes (Figure 1C). To validate this we determined 


\section{A}
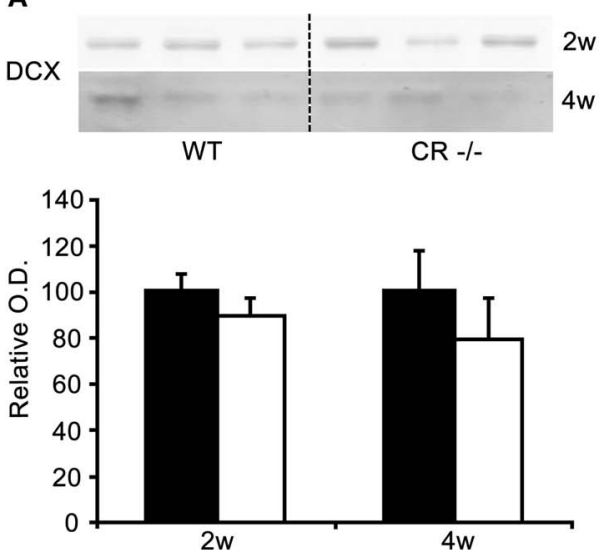

C
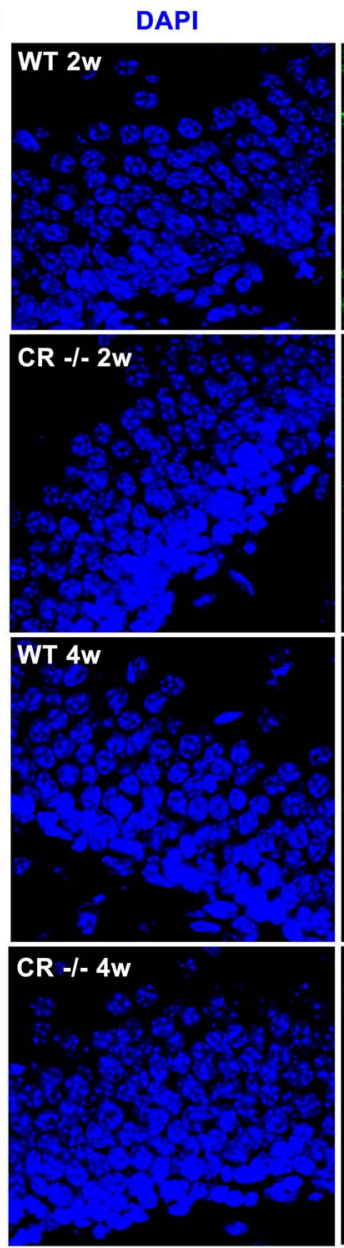

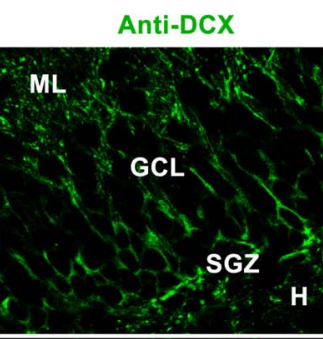

ML
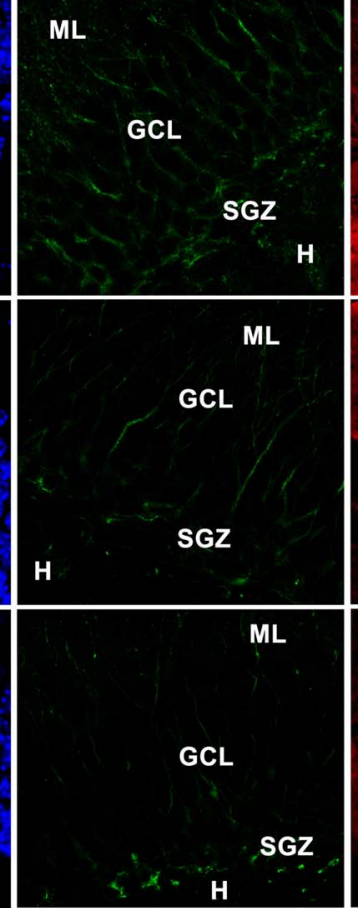
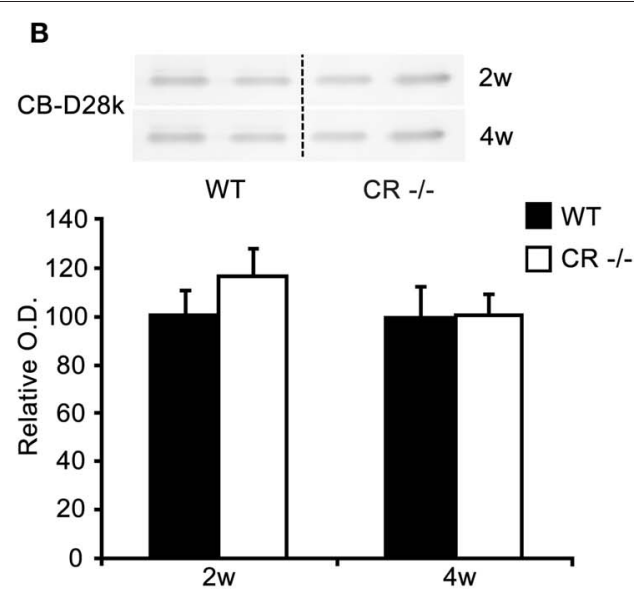

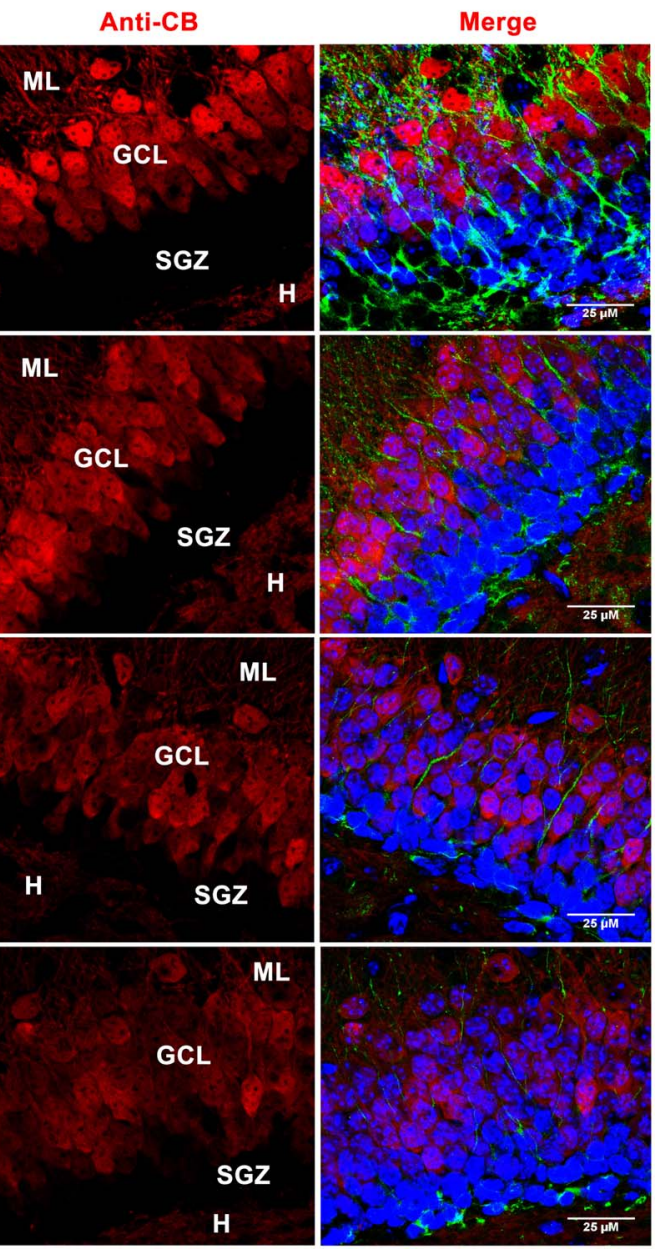

FIGURE 1 | Changes in DCX-immunoreactivity in cells in the GCL at 2 and 4 weeks in $\mathbf{C R}^{-/-}$mice. (A) Representative Western blots for DCX of whole hippocampi from $3 \mathrm{WT}$ and $3 \mathrm{CR}^{-/-}$mice at the age of 2 and 4 weeks (2w, 4w; upper panel). Densitometric analysis (lower panel) show that global DCX protein levels are not different between WT and $\mathrm{CR}^{-/-}(2 \mathrm{~W}: n=5$ per genotype; $4 \mathrm{w}: n=3$ per genotype). (B) Absence of CR does not affect hippocampal CB expression levels ( $2 \mathrm{w} n=5$ per genotype; $4 \mathrm{w} n=3$ per genotype). (C) Double immunolabeling with DCX (green) and CB (red) on sections from 2 and 4 weeks old mice counterstained with DAPI (blue).
Note the weaker staining for DCX in both cell somata and processes in 2 weeks old $\mathrm{CR}^{-1-}$ mice. The differences in intensity in the cell bodies between WT and $\mathrm{CR}^{-/-}$mice appear to level out within the two following weeks. However, in 4 weeks old $\mathrm{CR}^{-/-}$mice DCX-immunoreactivity remains weak in the dendritic processes. CB labeling intensity of granule cells is rather variable and is not linked to either age or genotype, for details see Results. Scale bar: $25 \mu \mathrm{m}$. Abbreviations: CR: calretinin, GCL: granule cell layer, $\mathrm{H}$ : hilus region, ML: molecular layer, O.D: optical density, SGZ: subgranular zone, w: week. 
the intensity values per pixel of dendritic profiles and cell bodies in selected images of each group at this age. Mean ratio values of DCX intensity (dendritic/somatic) amounted to $0.52 \pm 0.05$ for WT and were significantly reduced to $0.26 \pm 0.05$ in $\mathrm{CR}^{-/-}$ $(p=0.015)$. Selective confinement or redistribution of DCX to the cell bodies observed in $\mathrm{CR}^{-/-}$mice may well occur without affecting total protein content and may reflect changes in the regulation of DCX binding to the cytoskeleton critical for its functions (Bilimoria et al., 2010; Jin et al., 2010).

Since most DCX-labeled cells within the SGZ belong to cycling progenitors rather than to early postmitotic neurons (von Bohlen Und Halbach, 2011), we decided to further explore functional changes in this population by investigating the proliferative activity in the DG SGZ of $\mathrm{CR}^{-/-}$mice. We adopted PCNA, a wellknown marker for dividing cells (Miyachi et al., 1978; Ino and Chiba, 2000). Western blots of whole hippocampus lysates of $\mathrm{CR}^{-/-}$and WT mice revealed a decrease in protein content in $\mathrm{CR}^{-/-}$mice. Densitometric analysis evidenced a significant decrease of 35\% in PCNA protein content in 4-weeks old animals $(p<0.05)$, but not in 2-weeks old ones (Figure 2).

We looked, therefore, for more localized and detailed changes by IHC in young (2-4 weeks old) as well as in adult animals (14 weeks). PCNA-immunoreactive (-ir) cells were mostly distributed in the SGZ of the DG below the GCL (Figure 3A). These proliferating cells may correspond in part to the few radial glia cells with putative stem cell function as well as to the more numerous and more rapidly cycling granule cell progenitors (Ino and Chiba, 2000). Since the number of PCNA-positive cells decreased with increasing age in both genotypes (Figure 3A), we determined their density in three coronal sections through the septal/dorsal DG for comparisons (Figure 3B). Density estimates

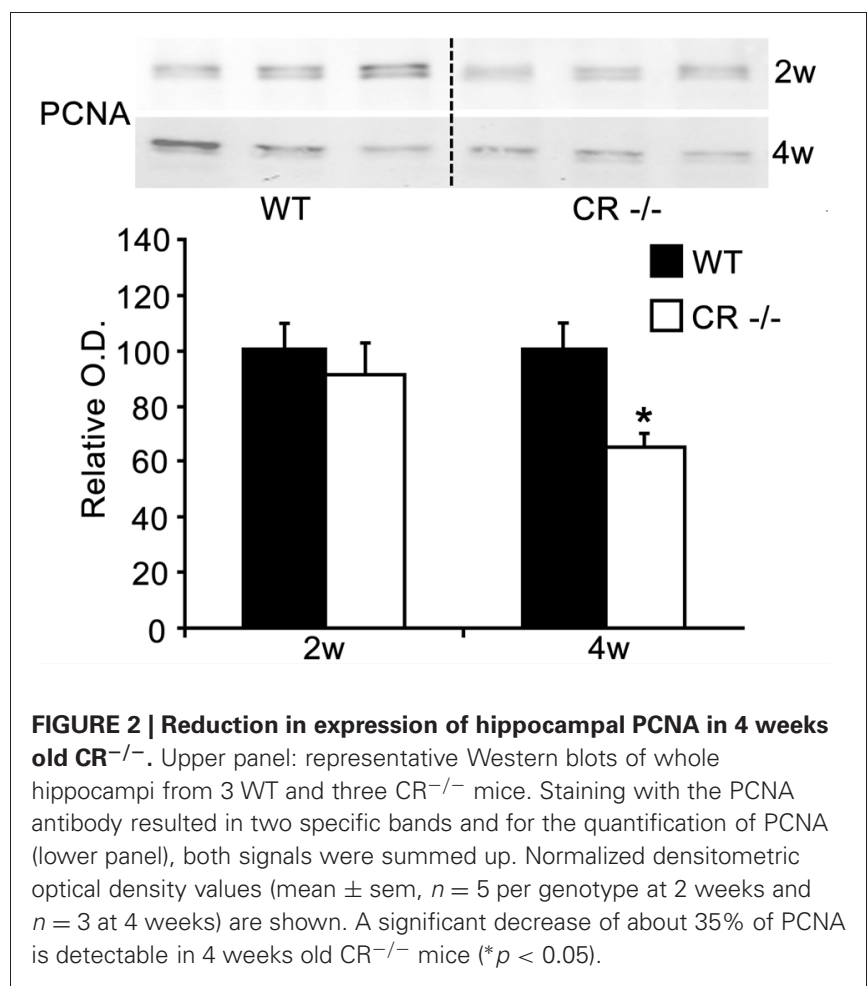

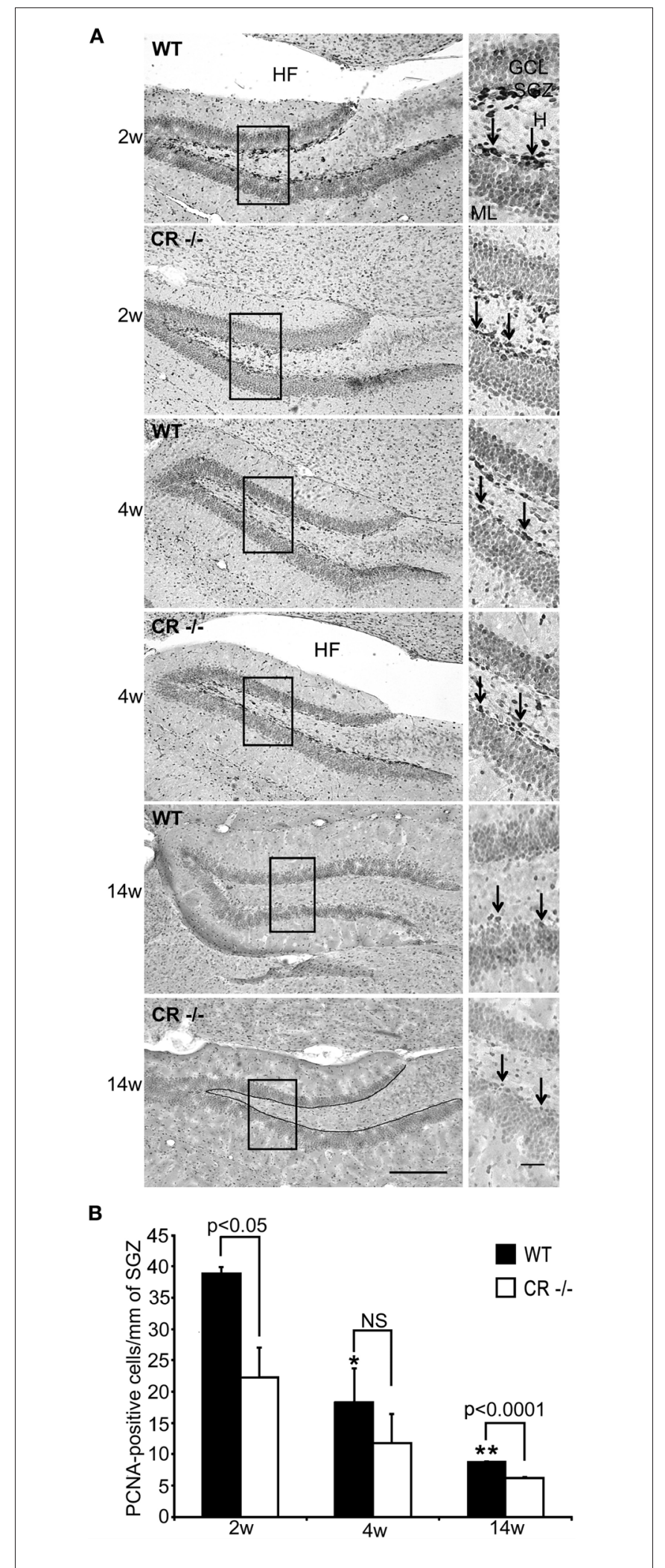

FIGURE 3 | Density of PCNA-ir cells in the septal DG stem cell niche is reduced in $\mathbf{C R}^{-/-}$mice. (A) Representative sections from the DG of $\mathrm{WT}$ and $\mathrm{CR}^{-1-}$ mice immunostained for PCNA and counterstained.

(Continued) 


\begin{abstract}
FIGURE 3 | Continued
High-resolution micrographs (scale bar: $10 \mu \mathrm{m}$ ) accompany each overview (scale bar: $100 \mu \mathrm{m}$ ) and correspond to the boxed areas. At the age of 2 weeks PCNA-ir cells (arrows in insets) are numerous and well visible, both in WT and $\mathrm{CR}^{-1-}$ mice. They are located in the SGZ at the inner border of the GCL. Positive cells appear less distinct and are less numerous with increasing age. The line drawn in the bottom overview image exemplifies the length measurements and marks the zone selected for the cell counts. (B) Density estimates of PCNA-ir cells are highest in 2 weeks old WT animals and significantly decrease at 4 and 14 weeks (* $4 \mathrm{w}$ vs. $2 \mathrm{~W}$ $p<0.05 ;{ }^{* *} 14 w$ vs. $2 w p<0.01$ ). A similar time-dependent decrease is also observed in $\mathrm{CR}^{-1-}$ mice, although differences did not reach statistical significance. Note that the density of PCNA-ir cells is significantly lower in $\mathrm{CR}^{-1-}$ as compared to WT animals at 2 weeks $(-40 \%)$ and 14 weeks $(-30 \%) . N=3$ for both genotypes at each data point. Abbreviations: see Figure 1; HF: hippocampal fissure.
\end{abstract}

of mitotically active cells were highest in young WT animals ( 2 weeks) and significantly decreased by $50 \%$ within the 2 successive weeks $(p<0.05)$. A further significant loss of $52 \%$ followed between the first and the third postnatal month of life $(p<0.01)$. A similar, time-dependent decrease was also seen in sections from $\mathrm{CR}^{-/-}$mice, although not reaching statistical significance. Strikingly, the density of PCNA-ir cells was significantly lower in $\mathrm{CR}^{-1-}$ mice as compared to WT animals at 2 weeks $(-40 \%)$ and 14 weeks $(-30 \%)$.

We then used alternative markers to confirm and explore in more detail this early decrease in proliferative matrix occurring in $\mathrm{CR}^{-/-}$mice. The BrdU uptake into dividing cells was tested in 2 weeks old WT and $\mathrm{CR}^{-/-}$mice, which were sacrificed $24 \mathrm{~h}$ after a single intraperitoneal BrdU injection. BrdU-ir nuclei within the SGZ of both WT and $\mathrm{CR}^{-/-}$were more intensely labeled as compared to the PCNA labeling (Figure 4A, compare with Figure 3A). In absolute terms, the number of BrdU-positive, i.e., dividing cells in the SGZ was larger than the number of PCNA-ir neurons in 2 weeks old WT animals (compare Figure 4B and Figure 3B). Quantification of BrdU-labeled dividing cells in the SGZ of WT and $\mathrm{CR}^{-/-}$mice showed a significant reduction in $\mathrm{CR}^{-/-}$mice by about $25 \%$ (Figure $4 \mathrm{~B} ; p<0.03$ ), analogous to the reduction observed by PCNA staining.

TCF- 4 was selected in 2 weeks and 4 weeks old mice as an additional marker for proliferating neuronal progenitor cells in the SGZ to consolidate the PCNA and BrdU data. TCF-4 is a basic-helix-loop-helix transcription factor activated by the canonical Wnt signaling pathway (Clevers, 2006). In the postnatal and adult DG, TCF-4 is expressed in DCX-positive granule cell progenitors (Lie et al., 2005; Kuwabara et al., 2009). In both WT and $\mathrm{CR}^{-/-}$sections, TCF-4 immunoreactivity was rather weak, but restricted to specific nuclei of cells located in the SGZ (Figure 5A). Quantification of TCF-4-positive nuclei showed a significant decrease $\left(-26 \%\right.$, Figure 5B) in 2 weeks old $\mathrm{CR}^{-/-}$ mice, thus in line with the PCNA and BrdU results. As for the PCNA staining (Figure 3B), no significant differences between genotypes persisted in 4 weeks old mice.

Altogether these data strongly suggest that $\mathrm{CR}^{-/-}$mice present a defect in proliferative capacity in the SGZ of the DG. Loss of proliferative activity is particularly evident and consistent at the early age of 2 weeks and seems to be maintained into adult life.

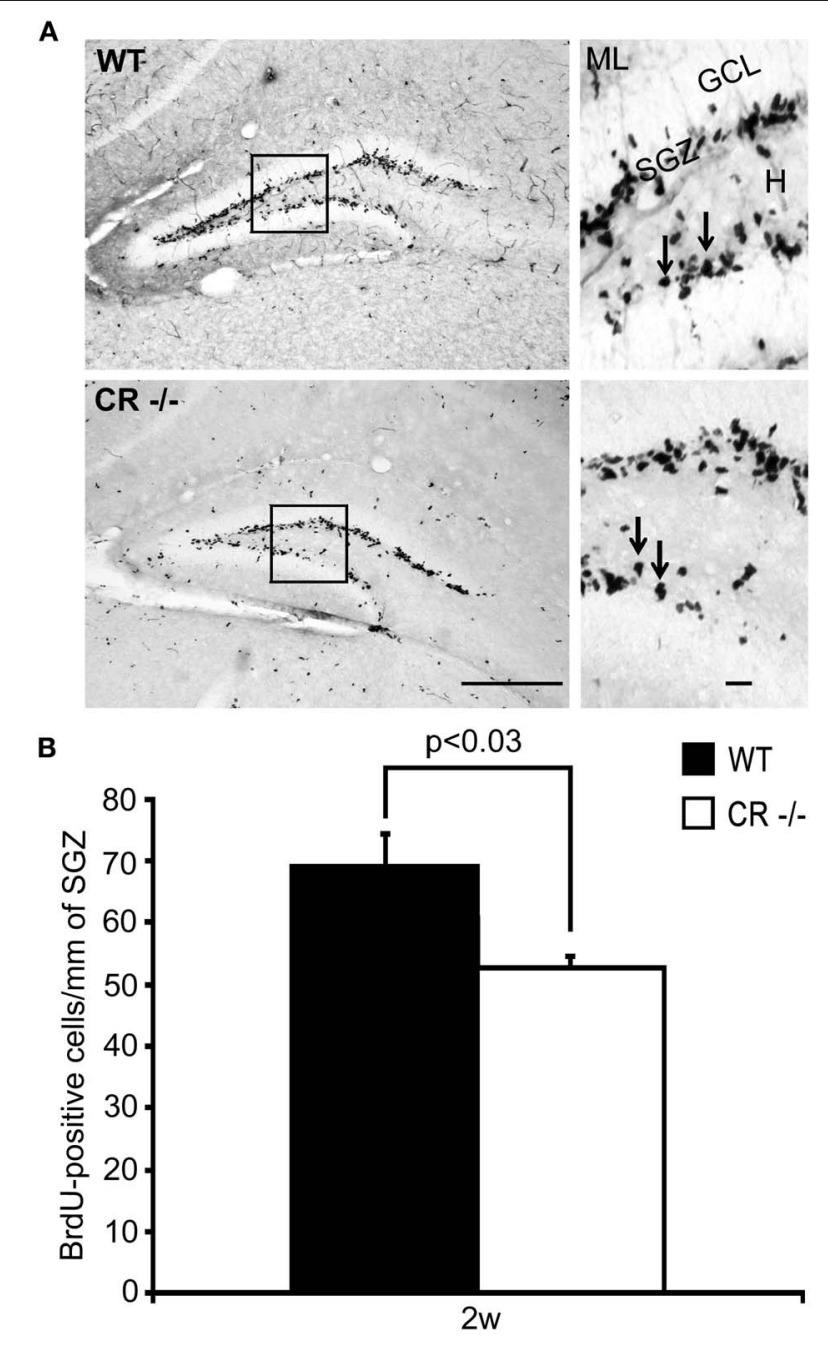

FIGURE 4 | Density of BrdU-ir cells in the septal DG stem cell niche is decreased in $\mathbf{2}$ weeks old $\mathbf{C R}^{-/-}$mice. (A) Overview of the distribution of BrdU-ir cells in the SGZ of the DG in WT (upper panel) and $\mathrm{CR}^{-/-}$(lower panel) mice. High-resolution micrographs (scale bar: $10 \mu \mathrm{m}$ ) correspond to the boxed areas in the overviews (scale bar: $100 \mu \mathrm{m}$ ). Arrows point to individual labeled cells. (B) Estimate of proliferating cells in the DG neurogenic niche, determined $24 \mathrm{~h}$ after a single BrdU pulse. Density estimates of BrdU-labeled cells are significantly reduced $(-24 \%)$ in 2 weeks old $\mathrm{CR}^{-/-}(n=4)$ mice as compared to WT $(n=6)$. Abbreviations: see Figure 1.

\section{LOW PROLIFERATIVE CAPACITY IN THE ADULT SGZ OF CR-/- MICE AFFECTS SURVIVAL OF NEWBORN GRANULE CELLS AND SLOWS DOWN THEIR MIGRATION INTO THE GCL}

To explore more in detail the consequences of such a loss in proliferative capacity at adult age we performed a BrdU differentiation assay and evaluated the 2 week survival/differentiation capacity of cells born in the SGZ at 12 weeks of age. BrdU-ir cells detected with this protocol were sparser in both WT and in $\mathrm{CR}^{-/-}$mice, compared to those detected by the proliferation assay performed at 2 weeks of age (Figure 6A, compare with Figure 4A). We thus counted the BrdU-positive nuclei in serial sections along the whole septotemporal extent of the DG to determine differences 


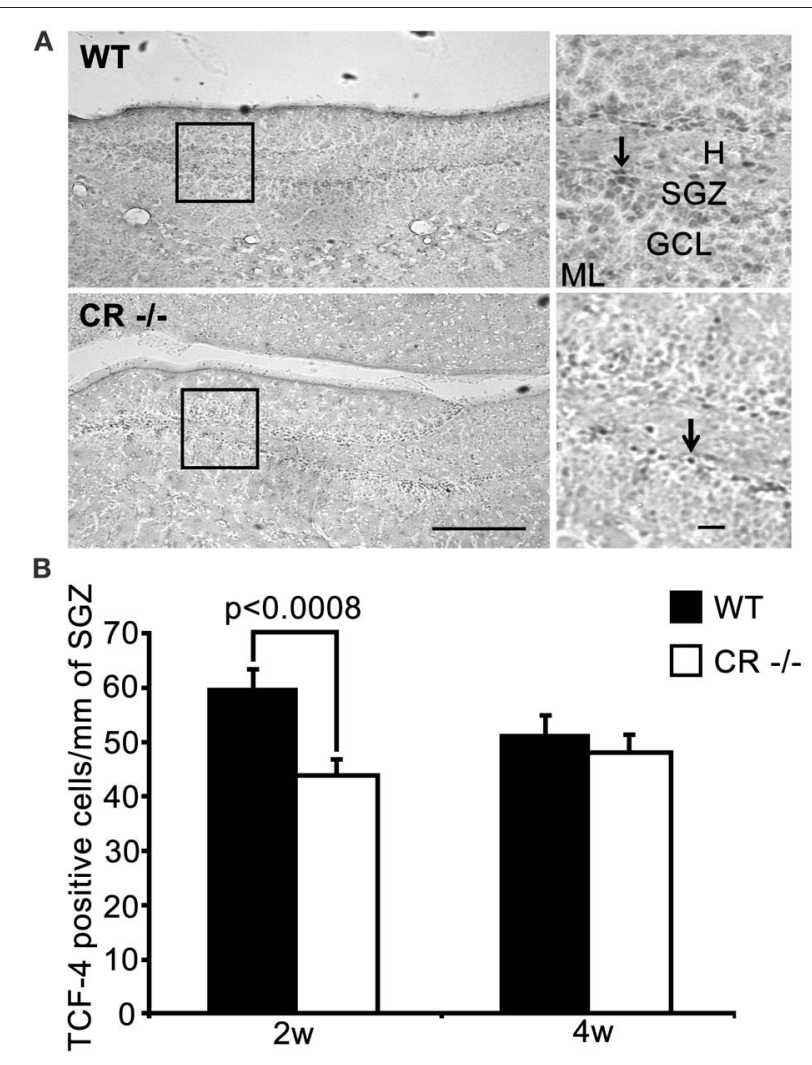

FIGURE 5 | TCF-4-ir cells responsive to proliferative signals are significantly decreased in the SGZ of 2 weeks old $\mathrm{CR}^{-/-}$mice. (A) Overview of the distribution of TCF-4 positive cells in the SGZ of the DG in WT (upper panel) and $\mathrm{CR}^{-/-}$(lower panel) mice. High-resolution micrographs (scale bar: $10 \mu \mathrm{m}$ ) correspond to the boxed areas in the overviews (scale bar: $100 \mu \mathrm{m}$ ). Arrows point to individual TCF-4-ir cells. (B) The density estimates of the putative progenitor pool expressing TCF-4 differ significantly in 2 weeks old mice $\left(-26.6 \%\right.$ of WT in $\left.\mathrm{CR}^{-1-}\right)$. The initial decrease in TCF-4-ir cells does not persist in 4 weeks old $\mathrm{CR}^{-1-}$ mice. $N=4$ per genotype and age. Abbreviations: see Figure 1.

in the mean total number between genotypes. We found that the survival and differentiation of newborn cells in the adult SGZ niche of $\mathrm{CR}^{-/-}$mice was significantly reduced by a factor of 2 as compared to WT (Figure 6B). In WT about $53 \%$ of the nuclei were localized in the SGZ, while in $\mathrm{CR}^{-/-}$mice this fraction amounted to $64 \%$. Those BrdU-ir nuclei located within the GCL amounted to $36 \%$ for WT and corresponded to only $28 \%$ of the total in $\mathrm{CR}^{-/-}$. Similarly, the relative fraction of BrdU-ir cells close to the ML was smaller in $\mathrm{CR}^{-/-}$mice $(8 \%)$ as compared to the $11 \%$ of WT (Figures 6C-D). These data suggest that migration of progenitor cells out of the SGZ into the inner GCL is hampered in the absence of $\mathrm{CR}$, affecting in turn the migration process of differentiating granule cells throughout the GCL. To further explore this possibility, values for WT and $\mathrm{CR}^{-/-}$ presented in Figure 6D were normalized within each genotype, plotted against the relative migration (Figure 6E) and the slope of the linear regression was taken as a proxy measure for migration, i.e., the steeper the slope, the lower cell migration. The slope for $\mathrm{CR}^{-/-}$mice was approximately $40 \%$ larger $\left(-56.8\right.$ in $\mathrm{CR}^{-/-}$ vs. -41.3 in WT) supporting the hypothesis of slower/reduced migration of newly generated granule cells. Overall, the mean cell number of BrdU-ir cells was significantly lower at each location in $\mathrm{CR}^{-/-}$mice as compared to WT animals $(p<0.02-0.05$; Figures 6C-D). These data indicate that the prolonged failure in proliferative activity into adult age observed in the SGZ of $\mathrm{CR}^{-/-}$ may negatively influence the survival of postmitotic neurons.

Double labeling of BrdU and CR, respectively $\mathrm{CB}$ was performed to evaluate the extent of differentiation that these newborn cells generally undergo in WT mice in the time period of 2 weeks after the last BrdU injection. BrdU-positive nuclei were not found to colocalize with $\mathrm{CB}$-ir mature granule cells (Figure 6F), while BrdU and CR co-localization in immature granule cells distributed at the inner border of the GCL was observed at a variable rate $(39 \pm 21 \%$; e.g., Figure 6G), in agreement with the reported temporal expression patterns for BrdU-labeled, CR-positive neurons in WT mice (approx. 30\% at 2.5 weeks; Kempermann et al., 1997; Brandt et al., 2003). In $\mathrm{CR}^{-/-}$mice, the approximate timeline of appearance of $\mathrm{CB}$ in new granule cells was similar as in WT mice, i.e., no CB and BrdU co-localization was seen (data not shown). Thus, we conclude that the impaired migration process of the fewer cells in the $\mathrm{CR}^{-/-} 2$ weeks after birth is likely more affected than their differentiation as measured in terms of average time to onset of $\mathrm{CB}$ expression.

\section{NO EVIDENCE FOR CHANGES IN THE PROLIFERATIVE ACTIVITY OR CELL SURVIVAL IN THE SGZ OF CB $^{-/-}$MICE}

Since $\mathrm{CB}$ is expressed in mature granule cells, we investigated whether its absence in $\mathrm{CB}^{-/-}$mice also entails alterations in postnatal neurogenesis. We analyzed the total amount, the relative distribution and staining intensity in the SGZ of 2 weeks and 4 weeks old mice for DCX, as in the $\mathrm{CR}^{-/-}$mice. A weaker DCX staining mostly confined to cell bodies was observed in $\mathrm{CB}^{-/-}$mice, a staining pattern strongly reminiscent of the one present in $\mathrm{CR}^{-/-}$mice (compare Figure 7A with Figure 1C); in line with results in $\mathrm{CR}^{-/-}$mice, DCX protein levels were not different between WT and $\mathrm{CB}^{-/-}$mice (data not shown). In $\mathrm{CB}^{-/-}$ mice we used CR IHC to check the overall morphology of the subpopulation of postmitotic neurons that partly also express DCX. Neither immunostaining signal intensity and distribution (Figure 7A) nor CR protein expression levels (Figure 7B) were different between $\mathrm{CB}^{-/-}$and WT mice.

PCNA-ir cells in the SGZ showed a significant age-dependent decrease in both WT and $\mathrm{CB}^{-/-}$mice, most pronounced in the period from 2-4 weeks. A decrease in the density of PCNA-ir cells was observed only at the earliest time point (2 weeks) in $\mathrm{CB}^{-/-}$ mice in comparison to WT animals. So contrarily to what we observed in $\mathrm{CR}^{-/-}$animals, a long-term recovery of the proliferative capacity occurred in $\mathrm{CB}^{-/-}$mice (Figure 8A). Noteworthy, the BrdU proliferation assay at 2 weeks did not reveal significant differences between genotypes (Figure 8B, for details, see discussion). Analysis of the 2 weeks survival/differentiation assays (same as those reported for $\mathrm{CR}^{-/}$mice in Figure 6) did not show any differences between $\mathrm{CB}^{-/-}$and WT mice (Figure 8C). Accordingly, no differences with respect to the relative distribution of BrdU-ir cells in the different compartments SGZ, GCL, and GCL/ML were detected (data not shown); the values largely corresponded to those reported for WT in Figure 6D. 

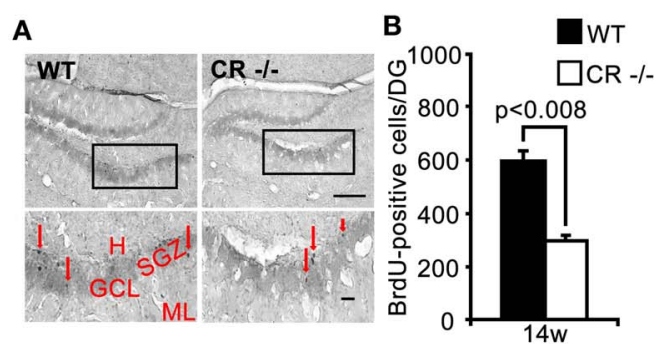

C

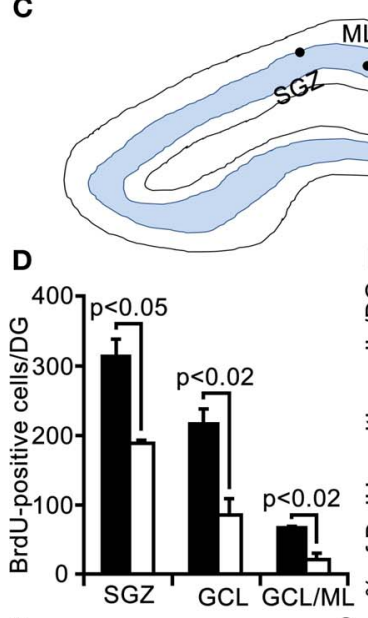

\section{$\mathrm{ML}$}

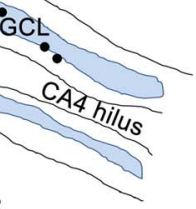

E

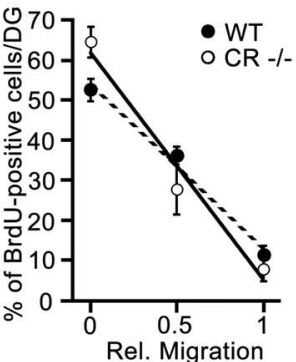

$\mathbf{F}$
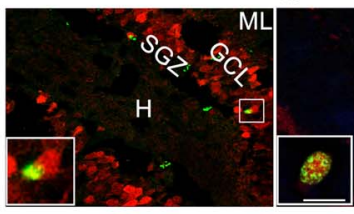

Red-Cy-5: CB-D28k

Green-Dylight 488: BrdU Green-Dylight 488: BrdU

FIGURE 6 | BrdU differentiation assay: survival of newborn cells is significantly reduced in adult $(14 \mathrm{w}) \mathrm{CR}^{-/-}$mice and the migration into the GCL is impaired. (A) Overview of the distribution of BrdU-ir cells in the DG of WT (left panel) and $\mathrm{CR}^{-1-}$ (right panel) mice. High-resolution micrographs (lower images, scale bar: $10 \mu \mathrm{m}$ ) correspond to the boxed areas in the overviews (scale bar: $100 \mu \mathrm{m}$ ). Red arrows point to individual BrdU-ir cells. (B) Bar graph plotting the mean total number of BrdU-ir cells determined along the whole septotemporal extent of the DG, 2 weeks after 3 daily BrdU pulses in adult 3 months old animals. The survival of newborn cells in $\mathrm{CR}^{-1-}$ is significantly reduced by a factor of 2 as compared to WT $(-50 \%, n=3$ per genotype). (C) Drawing of the DG (not scaled) exemplifying the layer distribution of BrdU-ir cells (black dots) 2 weeks after the last marker injection. (D) Layer specific counts of BrdU-ir nuclei are plotted for the two genotypes. In $\mathrm{CR}^{-/-}$the mean cell number is significantly lower than in WT at each location. (E) Relative distribution of BrdU-ir cells in SGZ (rel. migration: 0), in the GCL (rel. migration: 0.5) and in the border region GCL/ML (rel. migration: 1) of WT and $\mathrm{CR}^{-1-}$ mice. The slopes of the linear regression curves $\left(r^{2}=-0.99\right.$ for both genotypes) served as a proxy measure for migration of newborn granule cells. The steeper slope in $\mathrm{CR}^{-1-}$ mice is indicative of slower/reduced migration. (F-G) Double labeling of $\mathrm{BrdU}$ and $\mathrm{CB}(\mathbf{F})$ or $\mathrm{BrdU}$ and $\mathrm{CR}(\mathbf{G})$ in the $\mathrm{DG}$ of a representative adult WT animal evaluated 2 weeks after the last BrdU injection. BrdU-ir nuclei never colocalize with CB-ir granule cells (F); CR is expressed in approx. one third of BrdU-ir cells. Due to the low number of BrdU-ir cells per section, rarely more than $1-2$ double-labeled cells are observed on a given section; they are located at the inner border of the GCL (G). Scale bar: $50 \mu \mathrm{m}$. Boxed areas are shown enlarged as insets at the left bottom of the micrographs (scale bar: $10 \mu \mathrm{m}$ ). Abbreviations: see Figure $\mathbf{1}$

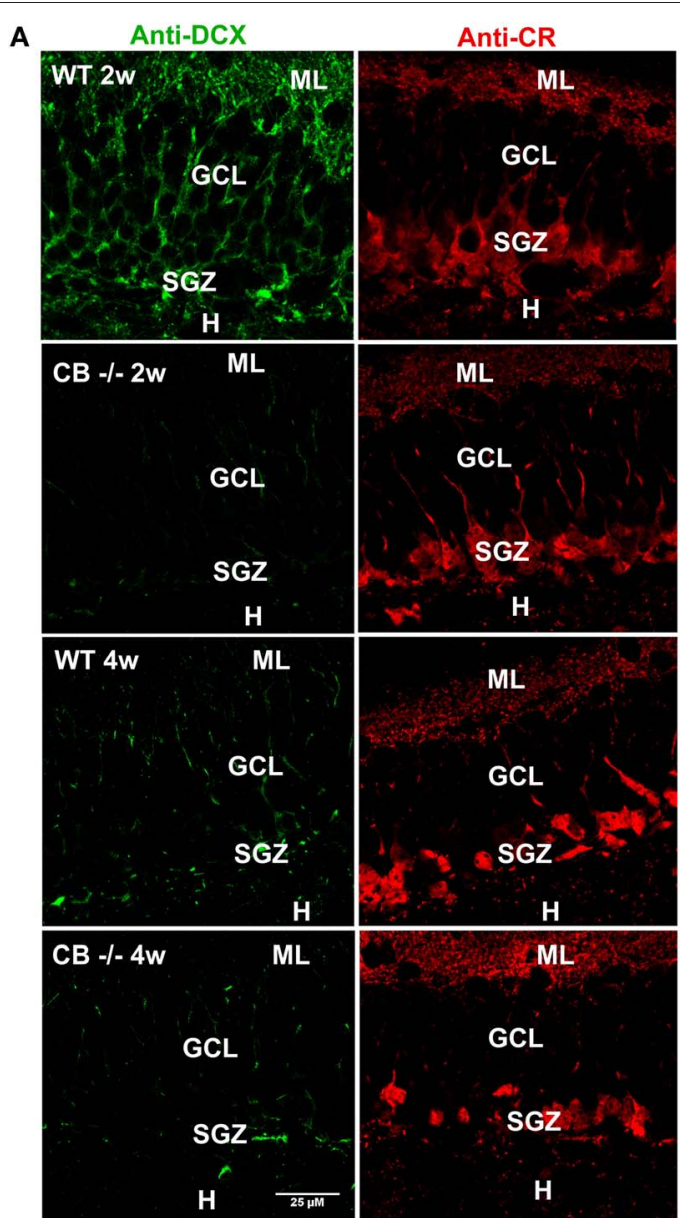

B

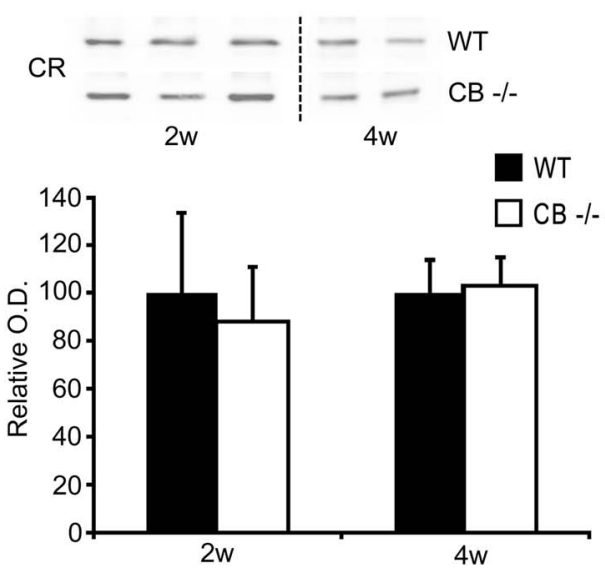

FIGURE 7 | No reduction in DCX and CR expression levels, but in DCX staining in 2-4 weeks old mice lacking CB. (A) Double immunolabeling with DCX (green, left panel) and CR (red, right panel). The images show details of the GCL and the SGZ for the 2 genotypes at 2 and 4 weeks. Note that the changes in DCX labeling intensity and intracellular signal distribution are the same as described for the $\mathrm{CR}^{-1-}$ in comparison to WT (Figure 1). No qualitative differences in CR-ir cells are visible between WT and $\mathrm{CB}^{-1-}$ at the two different time points. Scale bar: $25 \mu \mathrm{m}$.

(B) Representative Western blots for CR from WT and $\mathrm{CB}^{-1-}$ mice at the age of 2 and 4 weeks. Densitometric analysis reveals no differences between genotypes ( $2 \mathrm{w}: n=5$ per genotype; $4 \mathrm{w}: n=3$ per genotype). Abbreviations: see Figure 1 


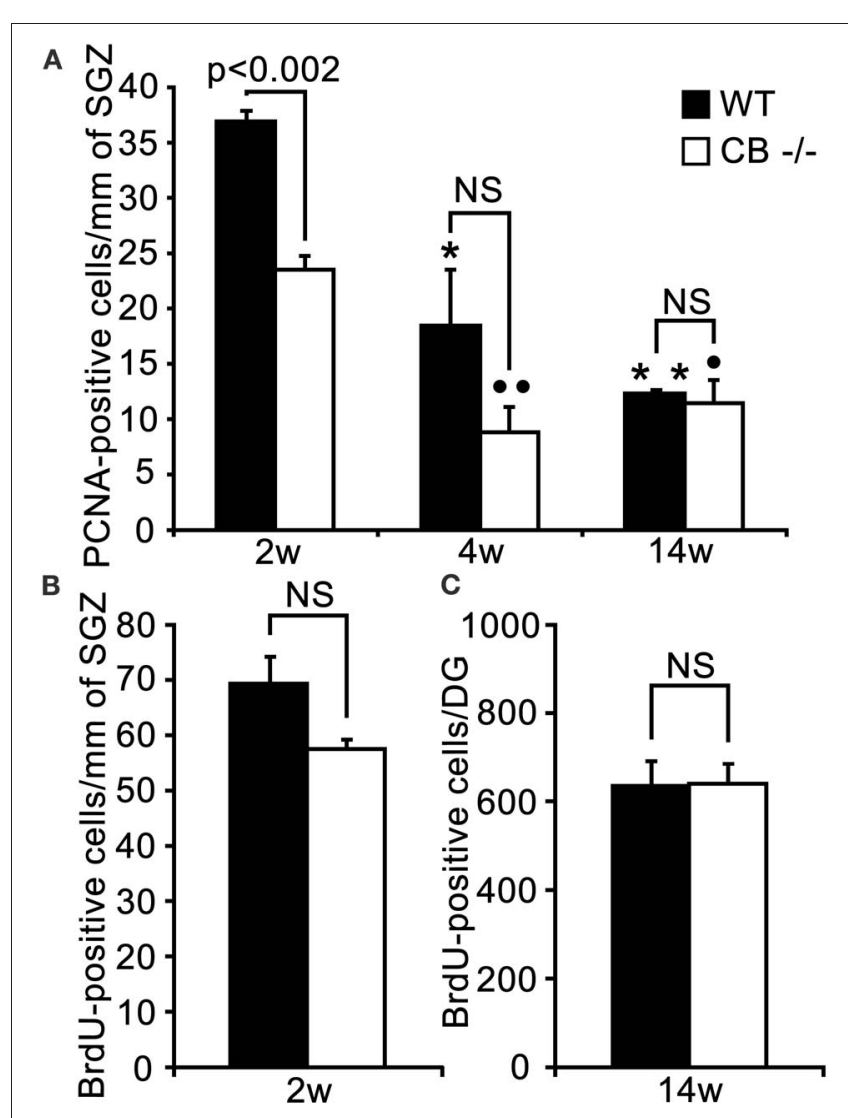

FIGURE 8 | An early putative deficit in proliferative activity in the DG cell stem niche of 2 weeks old $\mathrm{CB}^{-/-}$mice has no effect on survival/differentiation of granule cells in adult (14w) mice. (A) Density estimates of PCNA-ir cells in the septal extent of the SGZ of WT and $\mathrm{CB}^{-1-}$ mice. PCNA-ir cell density is highest in young (2 weeks) WT animals and decreases steadily and significantly in the successive 2 weeks. At the adult age of 3 months the density is reduced to one third of the initial value $\left({ }^{*} p<0.054\right.$ w vs. $2 w^{*}{ }^{* *} p<0.0114$ w vs. 2 w). In $\mathrm{CB}^{-/-}$mice a significant decrease is only observed from 2 to 4 weeks, while no changes occur from 4 to 14 weeks $\left({ }^{\circ} p<0.014 w\right.$ vs. $2 w$ and ${ }^{\circ} p<0.0514 w$ vs. $\left.2 w\right)$. The initial reduction in the density of PCNA-ir cells observed in 2 weeks old $\mathrm{CB}^{-/-}$ mice is not maintained at later time points $(4 \mathrm{w}$ and $14 \mathrm{w}) . N=3$ for both genotypes and ages. (B) Density of BrdU-ir nuclei determined $24 \mathrm{~h}$ after a single BrdU pulse in the septal SGZ. The small decrease in the density of BrdU-ir nuclei in 2 weeks old $\mathrm{CB}^{-1-}$ mice $(20 \%$ ) is not significant $(n=6$ mice per genotype). (C) Mean total number of BrdU-ir cells estimated along the whole septotemporal extent of the DG, 2 weeks after 3 daily BrdU pulses in adult 3 months old animals. The survival of newborn cells in $\mathrm{CB}^{-/-}$mice does not differ from WT mice ( $n=3$ per genotype).

These data indicate that loss of CB expression from DG granule cells as well as from the few hippocampal CB-ir interneurons (Gulyas and Freund, 1996) has no significant effect on the proliferative activity of progenitor cells nor affects survival and/or migration of newborn neurons within the adult SGZ.

\section{DISCUSSION}

We studied the impact that the constitutive absence of the $\mathrm{Ca}^{2+}$ binding proteins $\mathrm{CR}$ and $\mathrm{CB}$, mutually expressed at different stages of maturation of granule cells, may have on the proliferation and differentiation within the SGZ neurogenic niche of the
DG in null-mutant mice. Effects were evaluated at young age (2 weeks and 4 weeks) and in adult animals (3 months). The constitutive absence of CB expression from differentiated DG granule cells has no retrograde effect on the proliferative activity of progenitor cells, nor affects survival or migration/differentiation of newborn neurons in the adult DG including the SGZ. On the contrary, lack of CR from immature early postmitotic granule cells, causes an early loss in proliferative capacity of the SGZ that is maintained into adult age, when it has a further impact on the migration/survival of newborn granule cells.

\section{ABSENCE OF CR EXPRESSION IN NEWBORN GRANULE CELLS IMPAIRS THE PRECEDING PROGENITOR PROLIFERATION PHASE}

DCX is a microtubule-associated protein that promotes their polymerization. In the SGZ of the DG, DCX is transiently expressed in proliferating neural progenitors and in early postmitotic neurons expressing CR and NeuN (Brandt et al., 2003; Brown et al., 2003; von Bohlen Und Halbach, 2011). Thus, the pool of DCX-positive cells also includes to a minor extent cells exiting the cell cycle to become immature granule cells. Whole hippocampal DCX protein levels were similar in 2 and 4 weeks old $\mathrm{CR}^{-/-}$and $\mathrm{CB}^{-/-}$mice and did not differ from WT ones. However, compared to WT animals, differences in DCX distribution were evident at the morphological level: in 4 weeks old mutant mice, in particular, the intensity per pixel was significantly weaker in processes than in the cell bodies. DCX plays an active role in cytoskeletal assembly and process growth in immature neurons (Bilimoria et al., 2010; Jin et al., 2010). Such redistribution from dendritic processes to the cell body may therefore reflect a decrease of the cytoskeletal scaffold resulting in less and/or impaired growth of neuronal processes. Reduced process growth may eventually limit the capacity of sensing modulatory cues from the neighboring environment promoting targeting, network integration and survival. However, the changes in DCX-ir varied between genotypes and even between animals from the same genotype suggesting rapid redistribution dynamics and/or large inter-individual variety. A more detailed, possibly in vitro approach might be necessary to further investigate the putative role of DCX localization in neurogenesis in $\mathrm{CR}^{-/-}$and $\mathrm{CB}^{-/-}$ mice.

To address more directly the putative role of $\mathrm{CR}$ and $\mathrm{CB}$ in postnatal neurogenesis, PCNA and TCF-4 expression, as well as BrdU incorporation $24 \mathrm{~h}$ post injection were investigated. PCNA is a sliding clamp processivity factor, essential for fast replication of DNA during the S-phase of the cell cycle (Mathews et al., 1984). Therefore it is a well-known marker for dividing cells (Miyachi et al., 1978; Ino and Chiba, 2000); used as a complement or as an alternative to the classical $24 \mathrm{~h}$ BrdU proliferation assay. In line with previous reports (Ben Abdallah et al., 2010; Knoth et al., 2010), the density of proliferating cells in the SGZ considerably decreased with increasing age in WT mice. In 2 weeks old $\mathrm{CR}^{-/-}$mice densities of PCNA-ir and of BrdU-ir cells were much lower than in WT mice indicating a loss of the proliferating pool. Of note, in all experiments, the differences in density between WT and knockout mice were larger for PCNA-ir cells than for BrdU-ir cells (e.g., Figure 3B vs. Figure 4B). In the case of PCNA-ir, we reason that the lower contrast between the specific 
immunolabeling and the counterstaining led to an overestimation of differences. The BrdU-ir instead presented a better signal-tobackground contrast and thus reflects more accurately the real differences between genotypes.

TCF-4 is a basic-helix-loop helix transcription factor that mediates Wnt signaling by binding $\beta$-catenin and is considered to control downstream genes promoting cell proliferation and maintenance of the stem cell phenotype (Clevers, 2006). However, binding of additional proteins to the $\beta$-catenin/TCF- 4 complex within the nucleus may alternatively result in cell cycle exit and induction of differentiation programs (Teo et al., 2005; Teo and Kahn, 2010). Modulation of Wnt signaling plays a prominent role in CNS development (Michaelidis and Lie, 2008) and is critical for DG development. Its disruption causes the proliferative activity to stop prematurely and results in DG aplasia or hypoplasia (Galceran et al., 2000; Zhou et al., 2004). In the postnatal and adult DG, Wnt is secreted by astrocytes and continues to regulate the balance between proliferation and differentiation. TCF-4 is expressed within the SGZ, where it often colocalizes with DCX (Lie et al., 2005; Kuwabara et al., 2009). These cells may therefore correspond to the largely DCX-positive progenitor pool. Thus, we assumed a significant overlap between TCF-4-ir cells and the population determined by PCNA staining and BrdU incorporation. In accordance with the latter results, the density of TCF-4 positive cells was clearly decreased in 2 weeks old $\mathrm{CR}^{-/-}$ and the effect $(-27 \%$ compared to $\mathrm{WT})$ was in the same range as for PCNA staining $(-39 \%)$ and BrdU incorporation $(-24 \%)$. Therefore, the loss of proliferative capacity observed with PCNA and BrdU IHC in 2 weeks old $\mathrm{CR}^{-/-}$appears to affect progenitor cells that are sensitive to the Wnt signaling cascade and its modulators and which are about to decide on their fate (either reenter or exit the cell cycle).

Results in 4 weeks old $\mathrm{CR}^{-/-}$mice were less conclusive. The densities of PNCA-ir and TCF-4-ir cells were almost indistinguishable from those in WT mice, although the values were still slightly smaller. This may reflect an attempt to compensate the earlier loss of proliferative capacity. However, the significant reduction in whole hippocampal PCNA protein levels observed at this age rather suggests that compensation is not achieved. Adult neurogenesis is considered as a process that may be influenced at many different stages of neuronal development and showing a high degree of plasticity (Kempermann, 2011). Thus, it is not surprising that the initially rather large differences seen at 2 weeks in the absence of CR did not extend to the age of 4 weeks. The apparent inconsistencies with respect to PCNA, i.e., a decrease in PCNA-ir cells without significant changes in protein levels at 2 weeks and the opposite finding at 4 weeks may be the result of the low number of animals analyzed per group and of the larger variability in signal intensities of the PCNA Western blots. Considering all the investigated markers (TCF-4, PCNA, BrdU) we can conclude that the absence of CR expression in early postmitotic granule cells at the age of 2 weeks negatively affects neurogenesis, namely the preceding progenitor proliferation phase.

Once morphogenesis of the infrapyramidal blade of the DG is accomplished by the end of the first postnatal week, the proliferative matrix remains quite active for the following 2-3 weeks.
During this time period more granule cells are added to the network, i.e., to the inner third of the DG (Altman and Bayer, 1990a,b; Li and Pleasure, 2005). Meanwhile the proliferating pool in the SGZ changes and rearranges into the prospective adult state: the strictly genetic/intrinsic control-active during development is implemented with additional extrinsic modulatory cues derived from the functional DG network, e.g., synaptic activity and its dependent signaling as well as the overall metabolic state (Kempermann, 2011). It has been proposed that this transition period would be better-termed "childhood" or "adolescence" neurogenesis (Knoth et al., 2010). It is well possible that during this sensitive period of transition to adult neurogenesis, early postmitotic neurons may be the source of some extrinsic modulatory signals, which influence in a feedback mode the cycling activity of the progenitor pool. Within the adult SGZ, CR expression seems restricted to postmitotic cells, i.e., $\mathrm{CR}$ co-expression in BrdU-ir cells is never observed early (4 h) after BrdU injection (Brandt et al., 2003). In maturing granule cells, CR probably functions as a $\mathrm{Ca}^{2+}$ buffer and/or sensor during $\mathrm{Ca}^{2+}$ transients occurring in concomitance with the onset of synaptic activity and linked to the GABA-dependent depolarizing currents (Ge et al., 2006). It is plausible that within the $\mathrm{Ca}^{2+}$ signaling network typical of this stage (Jagasia et al., 2009; Merz et al., 2011) retrograde signals may be generated to regulate an antecedent phase. Speculatively, it could be assumed that during the time period of transient CR expression immature granule cells give a feedback to the progenitor pool with regard to their successful differentiation progress, thus regulating cell fate decision toward cell cycle reentry and further proliferation/amplification. CR deficiency in mutants would then hamper feedback signaling and eventually deliver instructions to the progenitor pool to regulate cell fate decision in the opposite direction. This would result in a more frequent/precocious cell cycle exit and eventually endanger amplification of the progenitor pool, thus exhausting the proliferative matrix. According to this scenario, the decrease in TCF- 4 expressing cells observed in $\mathrm{CR}^{-/-}$ mice suggests that such regulatory feedback may interfere with the Wnt/ $\beta$-catenin-TCF-4 signaling cascade, which is critical for cell fate decisions both during embryonic DG morphogenesis (Galceran et al., 2000; Zhou et al., 2004), as well as adult neurogenesis (Lie et al., 2005; Kuwabara et al., 2009). Further experiments are required to investigate the nature of the putative diffusible signals and to identifying the $\mathrm{Wnt} / \beta$-catenin-TCF- 4 cascade as a possible target.

\section{ABSENCE OF CR IN NEWBORN GRANULE CELLS SEVERELY DECREASES THEIR SURVIVAL AND LIKELY AFFECTS THE MIGRATION PROCESS}

We further examined adult animals, because by this time the lifelong steady-state levels of proliferation and differentiation typical of adult neurogenesis have been accomplished (Ben Abdallah et al., 2010; Knoth et al., 2010; Kempermann, 2011). In both WT and $\mathrm{CR}^{-/-}$mice, the density of PCNA-ir cells was much lower than in 2 weeks old animals and a clear difference $(-30 \%)$ in the density of PCNA-ir putative progenitor cells was observed in mice lacking CR. Thus, the deficit in proliferative capacity of the SGZ was maintained in adult $\mathrm{CR}^{-/-}$mice. To test whether 
such a permanent decrease in the progenitor pool would have any consequences on the survival and differentiation of newborn neurons in adult mice a BrdU differentiation essay was performed. The number and distribution of BrdU-positive cells within the SGZ and the GCL were determined 2 weeks after administration of the substance in adult mice. BrdU-labeled neurons were reduced by a factor of two in $\mathrm{CR}^{-/-}$as compared to WT mice. A period of 2 weeks is not sufficient for BrdU-ir cells to express $\mathrm{CB}$, since it generally takes 4 weeks for newborn granule cells to express it (Kempermann et al., 1997). Transient CR expression reaches a maximum 1 week from birth of a newly generated granule cell; 2.5 and 4 weeks after birth, the percentage of BrdU-ir cells expressing CR is reduced to approximately 30 and 5\%, respectively, (Brandt et al., 2003). Since we did not observe changes in $\mathrm{CR}^{-/-}$mice regarding this timeline, we assume that most BrdU-ir cells detected in the survival/differentiation assay correspond to postmitotic neurons in the phase of active process growth and synaptogenesis (Ge et al., 2006; Toni and Sultan, 2011). Thus, the survival of the pool of newborn immature granule cells is drastically reduced in $\mathrm{CR}^{-/-}$mice.

Detailed analysis of the relative position of the BrdU-ir cells within the height of the adult SGZ and GCL in WT and $\mathrm{CR}^{-/-}$ mice revealed that in $\mathrm{CR}^{-/-}$a larger percentage of neurons remained confined to the SGZ. Accordingly the relative fraction of newborn cells distributed within the GCL was decreased. Migration out of the SGZ into the GCL seems to occur in 2 steps. In a first step, which is accomplished while exiting the cell cycle, all cells move out of the SGZ to reach the inner GCL. Then postmitotic cells further migrate within the GCL to different extents (Ming and Song, 2011; von Bohlen Und Halbach, 2011). Thus, we may conclude that those newborn cells detectable in the $\mathrm{CR}^{-/-}$by this assay exhibit a deficit in the migration process.

Critical prerequisites for the successful accomplishment of the different maturation steps are the GABA-mediated depolarization (Ge et al., 2006) and the related activation of CREB signaling (Merz et al., 2011). If the depolarizing effects of GABA are lost or CREB phosphorylation is reduced at this stage, then survival of the newborn neurons is at risk (Jagasia et al., 2009). As mentioned earlier, the presence of $\mathrm{CR}$ in newborn neurons largely coincides with the phase of sensitivity to the GABA-dependent depolarizing currents. Many studies in vivo and in vitro have demonstrated that $\mathrm{Ca}^{2+}$ buffers such as CR can affect processes like protein phosphorylation and/or dephosphorylation mediated by $\mathrm{Ca}^{2+} / \mathrm{CaM}$-dependent kinases or calcineurin, respectively, (Schwaller, 2010). CR may thus modulate depolarization-induced $\mathrm{Ca}^{2+}$ transients and subsequently affect CREB phosphorylation and in turn CREB-dependent activation of downstream targets promoting survival and further differentiation of newborn neurons (Merz et al., 2011). The specific and time-locked expression of CR at the onset of the differentiation stage in adult neurogenesis may thus play (1) a role on the self-maintenance signal for the pool of cells at the same stage contributing to their survival/differentiation, and (2) may contribute (as a retrograde signal) to the maintenance of the progenitor pool. Loss of CRmediated signaling would then reduce survival and eventually the size of the differentiating pool and compromise the proliferative function of progenitors.

\section{PHYSIOLOGICAL IMPLICATIONS OF CR'S ABSENCE IN DG PROGENITORS}

What would be the consequences of the hypothesized dual role of CR in terms of network function and of hippocampal dependent behavior? If we consider that in $\mathrm{CR}^{-/-}$mice the pool of immature granule cells which is particularly prone to exhibit synaptic plasticity (Deng et al., 2009; Mongiat et al., 2009) is only one half of that present in WT animals, then some effects at the network level are rather plausible. Thus, the deficient LTP induction specific to the DG of $\mathrm{CR}^{-/-}$mice (Schurmans et al., 1997) may well depend in part on the deficit in the number of immature granule cells and not solely on the loss of CR's $\mathrm{Ca}^{2+}$ buffering/sensing properties from terminals of the hilar mossy cell commissural associational pathway. An elegant approach to test this hypothesis would be to repeat the DG LTP study in mutants, where CR expression is only ablated in maturing granule cells. Numerous experimental and theoretical studies have accumulated in the last decades on the specific role of the DG within the hippocampal formation and its function at the behavioral level (Aimone et al., 2011). There is also increasing evidence that only a particular subset of hippocampal-dependent learning and their related behavioral tasks critically relies on normal adult neurogenesis (Treves et al., 2008; Aimone et al., 2011; Ming and Song, 2011). These are more likely tasks requiring encoding and association of events separated by time, rather than spatial learning tasks like those developed for the Morris water maze (Shors et al., 2001, 2002). Some impairment in spatial learning can also be detected, when adult neurogenesis is impaired, provided the time factor attains more relevance e.g., long-term retrieval in the water maze over days (Snyder et al., 2005). The behavioral tasks (spatial learning in the water maze and $24 \mathrm{~h}$ retrieval) as described in Schurmans et al. (1997) may therefore not be the ideal way to test the role of maturing neurons in learning and memory in $\mathrm{CR}^{-/-}$ animals.

Loss of proliferative capacity as shown here for $\mathrm{CR}^{-/-}$mice, may also have additive effects on the hypothesized deficits in LTP and DG-dependent learning and memory tasks. Cells not generated during early postnatal neurogenesis are then lacking at the stage of maturation and integration into the mature network and consequently curtailing the neurogenic reserve of the DG (Kempermann, 2008). We thus hypothesize that such deficits will worsen with age and either per se or in concomitance with neurodegenerative challenges will cause severe behavioral impairments much earlier in $\mathrm{CR}^{-/-}$than in WT mice.

\section{ACKNOWLEDGMENTS}

We would like to thank Simone Eichenberger, Dr. Sylvie Ducreux and Dr. Zoltan Mészár for technical assistance and W. Blum and Dr. T. Henzi, all from Anatomy, University of Fribourg for the critical reading of the manuscript. We would like to thank Dr. Olivier Raineteau, University of Zurich for the kind gift of TCF-4 antibody. This work was supported by the Swiss National Science Foundation (grant \# 130680 to Beat Schwaller). 


\section{REFERENCES}

Aimone, J. B., Deng, W., and Gage, F. H. (2011). Resolving new memories: a critical look at the dentate gyrus, adult neurogenesis, and pattern separation. Neuron 70, 589-596.

Airaksinen, M. S., Eilers, J., Garaschuk, O., Thoenen, H., Konnerth, A., and Meyer, M. (1997). Ataxia and altered dendritic calcium signaling in mice carrying a targeted null mutation of the calbindin D28k gene. Proc. Natl. Acad. Sci. U.S.A. 94, 1488-1493.

Altman, J., and Bayer, S. A. (1990a). Migration and distribution of two populations of hippocampal granule cell precursors during the perinatal and postnatal periods. J. Comp. Neurol. 301, 365-381.

Altman, J., and Bayer, S. A. (1990b). Mosaic organization of the hippocampal neuroepithelium and the multiple germinal sources of dentate granule cells. J. Comp. Neurol. 301, 325-342.

Baimbridge, K. G., Celio, M. R., and Rogers, J. H. (1992). Calciumbinding proteins in the nervous system. Trends Neurosci. 15, 303-308.

Ben Abdallah, N. M., Slomianka, L., Vyssotski, A. L., and Lipp, H. P. (2010). Early age-related changes in adult hippocampal neurogenesis in C57 mice. Neurobiol. Aging 31, 151-161.

Bilimoria, P. M., de La Torre-Ubieta, L., Ikeuchi, Y., Becker, E. B., Reiner, O., and Bonni, A. (2010). A JIP3regulated GSK3beta/DCX signaling pathway restricts axon branching. J. Neurosci. 30, 16766-16776.

Brandt, M. D., Jessberger, S., Steiner, B., Kronenberg, G., Reuter, K., BickSander, A., von der Behrens, W., and Kempermann, G. (2003). Transient calretinin expression defines early postmitotic step of neuronal differentiation in adult hippocampal neurogenesis of mice. Mol. Cell. Neurosci. 24, 603-613.

Brown, J. P., Couillard-Despres, S., Cooper-Kuhn, C. M., Winkler, J., Aigner, L., and Kuhn, H. G. (2003). Transient expression of doublecortin during adult neurogenesis. J. Comp. Neurol. 467, $1-10$.

Cheron, G., Gall, D., Servais, L., Dan, B., Maex, R., and Schiffmann, S. N. (2004). Inactivation of calciumbinding protein genes induces $160 \mathrm{~Hz}$ oscillations in the cerebellar cortex of alert mice. J. Neurosci. 24, 434-441.

Clevers, H. (2006). Wnt/beta-catenin signaling in development and disease. Cell 127, 469-480.
Deng, W., Saxe, M. D., Gallina, I. S., and Gage, F. H. (2009). Adultborn hippocampal dentate granule cells undergoing maturation modulate learning and memory in the brain. J. Neurosci. 29, 13532-13542.

Esposito, M. S., Piatti, V. C., Laplagne, D. A., Morgenstern, N. A., Ferrari, C. C., Pitossi, F. J., and Schinder, A. F. (2005). Neuronal differentiation in the adult hippocampus recapitulates embryonic development. J. Neurosci. 25, 10074-10086.

Farre-Castany, M. A., Schwaller, B., Gregory, P., Barski, J., Mariethoz, C., Eriksson, J. L., Tetko, I. V., Wolfer, D., Celio, M. R., Schmutz, I., Albrecht, U., and Villa, A. E. (2007). Differences in locomotor behavior revealed in mice deficient for the calcium-binding proteins parvalbumin, calbindin D-28k or both. Behav. Brain Res. 178, 250-261.

Faulkner, R. L., Jang, M. H., Liu, X. B., Duan, X., Sailor, K. A., Kim, J. Y., Ge, S., Jones, E. G., Ming, G. L., Song, H., and Cheng, H. J. (2008). Development of hippocampal mossy fiber synaptic outputs by new neurons in the adult brain. Proc. Natl. Acad. Sci. U.S.A. 105, 14157-14162.

Galceran, J., Miyashita-Lin, E. M., Devaney, E., Rubenstein, J. L., and Grosschedl, R. (2000). Hippocampus development and generation of dentate gyrus granule cells is regulated by LEF1. Development 127, 469-482.

Ge, S., Goh, E. L., Sailor, K. A., Kitabatake, Y., Ming, G. L., and Song, H. (2006). GABA regulates synaptic integration of newly generated neurons in the adult brain. Nature 439, 589-593.

Ge, S., Sailor, K. A., Ming, G. L., and Song, H. (2008). Synaptic integration and plasticity of new neurons in the adult hippocampus. J. Physiol. 586, 3759-3765.

Gulyas, A. I., and Freund, T. F. (1996). Pyramidal cell dendrites are the primary targets of calbindin D28kimmunoreactive interneurons in the hippocampus. Hippocampus 6, 525-534.

Gurden, H., Schiffmann, S. N., Lemaire, M., Bohme, G. A., Parmentier, M., and Schurmans, S. (1998). Calretinin expression as a critical component in the control of dentate gyrus long-term potentiation induction in mice. Eur. J. Neurosci. 10, 3029-3033.

Henze, D. A., and Buzsaki, G. (2007). Hilar mossy cells: functional identification and activity in vivo. Prog. Brain Res. 163, 199-216.
Ino, H., and Chiba, T. (2000). Expression of proliferating cell nuclear antigen (PCNA) in the adult and developing mouse nervous system. Brain Res. Mol. Brain Res. 78, 163-174.

Jagasia, R., Steib, K., Englberger, E., Herold, S., Faus-Kessler, T., Saxe, M., Gage, F. H., Song, H., and Lie, D. C. (2009). GABA-cAMP response element-binding protein signaling regulates maturation and survival of newly generated neurons in the adult hippocampus. J. Neurosci. 29, 7966-7977.

Jin, J., Suzuki, H., Hirai, S., Mikoshiba, K., and Ohshima, T. (2010). JNK phosphorylates Ser332 of doublecortin and regulates its function in neurite extension and neuronal migration. Dev. Neurobiol. 70, 929-942.

Kempermann, G. (2008). The neurogenic reserve hypothesis: what is adult hippocampal neurogenesis good for? Trends Neurosci. 31, 163-169.

Kempermann, G. (2011). Seven principles in the regulation of adult neurogenesis. Eur. J. Neurosci. 33, 1018-1024.

Kempermann, G., Kuhn, H. G., and Gage, F. H. (1997). Genetic influence on neurogenesis in the dentate gyrus of adult mice. Proc. Natl. Acad. Sci. U.S.A. 94, 10409-10414.

Knoth, R., Singec, I., Ditter, M., Pantazis, G., Capetian, P., Meyer, R. P., Horvat, V., Volk, B., and Kempermann, G. (2010). Murine features of neurogenesis in the human hippocampus across the lifespan from 0 to 100 years. PLoS One 5:e8809. doi: 10.1371/journal.pone.0008809

Kuwabara, T., Hsieh, J., Muotri, A., Yeo, G., Warashina, M., Lie, D. C., Moore, L., Nakashima, K., Asashima, M., and Gage, F. H. (2009). Wnt-mediated activation of NeuroD1 and retro-elements during adult neurogenesis. Nat. Neurosci. 12, 1097-1105.

Li, G., and Pleasure, S. J. (2005). Morphogenesis of the dentate gyrus: what we are learning from mouse mutants. Dev. Neurosci. 27, 93-99.

Lie, D. C., Colamarino, S. A., Song, H. J., Desire, L., Mira, H., Consiglio, A., Lein, E. S., Jessberger, S., Lansford, H., Dearie, A. R., and Gage, F. H. (2005). Wnt signalling regulates adult hippocampal neurogenesis. Nature 437, 1370-1375.

Mathews, M. B., Bernstein, R. M., Franza, B. R. Jr., and Garrels, J. I. (1984). Identity of the proliferating cell nuclear antigen and cyclin. Nature 309, 374-376.
Merz, K., Herold, S., and Lie, D. C. (2011). CREB in adult neurogenesis-master and partner in the development of adult-born neurons? Eur. J. Neurosci. 33, 1078-1086.

Michaelidis, T. M., and Lie, D. C. (2008). Wnt signaling and neural stem cells: caught in the Wnt web. Cell Tissue Res. 331, 193-210.

Ming, G. L., and Song, H. (2011). Adult neurogenesis in the mammalian brain: significant answers and significant questions. Neuron 70, 687-702.

Miyachi, K., Fritzler, M. J., and Tan, E. M. (1978). Autoantibody to a nuclear antigen in proliferating cells. J. Immunol. 121, 2228-2234.

Mongiat, L. A., Esposito, M. S., Lombardi, G., and Schinder, A. F. (2009). Reliable activation of immature neurons in the adult hippocampus. PLoS One 4:e5320. doi: 10.1371/journal.pone.0005320

Moreno, H., Burghardt, N. S., Vela, D., Mascotti, J., Hua, F., Fenton, A. A., Schwaller, B., and Small, S. A. (2011). Reductions in the calciumbuffering protein calbindin correlate with age-related hippocampal metabolic decline. Hippocampus. doi: 10.1002/hipo.20957. [Epub ahead of print].

Plumpe, T., Ehninger, D., Steiner, B., Klempin, F., Jessberger, S., Brandt, M., Romer, B., Rodriguez, G. R., Kronenberg, G., and Kempermann, G. (2006). Variability of doublecortin-associated dendrite maturation in adult hippocampal neurogenesis is independent of the regulation of precursor cell proliferation. BMC Neurosci. 7, 77.

Schiffmann, S. N., Cheron, G., Lohof, A., D'alcantara, P., Meyer, M., Parmentier, M., and Schurmans, S. (1999). Impaired motor coordination and Purkinje cell excitability in mice lacking calretinin. Proc. Natl. Acad. Sci. U.S.A. 96, 5257-5262.

Schurmans, S., Schiffmann, S. N., Gurden, H., Lemaire, M., Lipp, H. P., Schwam, V., Pochet, R., Imperato, A., Bohme, G. A., and Parmentier, M. (1997). Impaired long-term potentiation induction in dentate gyrus of calretinin-deficient mice. Proc. Natl. Acad. Sci. U.S.A. 94, 10415-10420.

Schwaller, B. (2009). The continuing disappearance of "pure" $\mathrm{Ca}^{2+}$ buffers. Cell. Mol. Life Sci. 66, 275-300.

Schwaller, B. (2010). Cytosolic $\mathrm{Ca}^{2+}$ buffers. Cold Spring Harb. Perspect. Biol. 2, a004051.

Schwaller, B., Tetko, I. V., Tandon, P., Silveira, D. C., Vreugdenhil, M., 
Henzi, T., Potier, M. C., Celio, M. R., and Villa, A. E. (2004). Parvalbumin deficiency affects network properties resulting in increased susceptibility to epileptic seizures. Mol. Cell. Neurosci. 25, 650-663.

Shors, T. J., Miesegaes, G., Beylin, A., Zhao, M., Rydel, T., and Gould, E. (2001). Neurogenesis in the adult is involved in the formation of trace memories. Nature 410, 372-376.

Shors, T. J., Townsend, D. A., Zhao, M., Kozorovitskiy, Y., and Gould, E. (2002). Neurogenesis may relate to some but not all types of hippocampal-dependent learning. Hippocampus 12, 578-584.

Snyder, J. S., Hong, N. S., Mcdonald, R. J., and Wojtowicz, J. M. (2005). A role for adult neurogenesis in spatial long-term memory. Neuroscience 130, 843-852.
Stadler, F., Schmutz, I., Schwaller, B., and Albrecht, U. (2010). Lack of calbindin-D28k alters response of the murine circadian clock to light. Chronobiol. Int. 27, 68-82.

Teo, J. L., and Kahn, M. (2010). The Wnt signaling pathway in cellular proliferation and differentiation: a tale of two coactivators. Adv. Drug Deliv. Rev. 62, 1149-1155.

Teo, J. L., Ma, H., Nguyen, C., Lam, C., and Kahn, M. (2005). Specific inhibition of $\mathrm{CBP} /$ beta-catenin interaction rescues defects in neuronal differentiation caused by a presenilin1 mutation. Proc. Natl. Acad. Sci. U.S.A. 102, 12171-12176.

Toni, N., and Sultan, S. (2011). Synapse formation on adult-born hippocampal neurons. Eur. J. Neurosci. 33, 1062-1068.
Treves, A., Tashiro, A., Witter, M. E., and Moser, E. I. (2008) What is the mammalian dentate gyrus good for? Neuroscience 154, 1155-1172.

von Bohlen Und Halbach, O. (2011) Immunohistological markers for proliferative events, gliogenesis, and neurogenesis within the adult hippocampus. Cell Tissue Res. 345, 1-19.

Zhou, C. J., Zhao, C., and Pleasure, S J. (2004). Wnt signaling mutants have decreased dentate granule cell production and radial glial scaffolding abnormalities. J. Neurosci. 24, 121-126.

Conflict of Interest Statement: The authors declare that the research was conducted in the absence of any commercial or financial relationships that could be construed as a potential conflict of interest.

Received: 20 February 2012; paper pending published: 09 March 2012; accepted: 05 April 2012; published online: 23 April 2012.

Citation: Todkar K, Scotti AL and Schwaller B (2012) Absence of the calcium-binding protein calretinin, not of calbindin D-28k, causes a permanent impairment of murine adult hippocampal neurogenesis. Front. Mol. Neurosci. 5:56. doi: 10.3389/fnmol.2012.00056 Copyright (C) 2012 Todkar, Scotti and Schwaller. This is an open-access article distributed under the terms of the Creative Commons Attribution Non Commercial License, which permits noncommercial use, distribution, and reproduction in other forums, provided the original authors and source are credited. 